\title{
Science for the Future: The Use of Citizen Science in Marine Research and Conservation
}

\author{
Hannah S. Earp and Arianna Liconti
}

\begin{abstract}
Over the last decade, significant advances in citizen science have occurred, allowing projects to extend in scope from the ocean floor to the Milky Way and cover almost everything in between. These projects have provided costeffective means to collect extensive data sets covering vast spatio-temporal scales that can be used in scientific research, to develop conservation policy and to promote environmental awareness. This review explores the current status of marine citizen science by examining 120 marine citizen science projects. Trends in geographic locations, focal taxa, participant demographics, tasks undertaken and data directionality (i.e. storage and publication) are highlighted, and the challenges and benefits of citizen science to marine research and conservation are reviewed. Marine citizen science projects act primarily at national levels (53.3\%) and mainly focus on coastal ocean environments (49.2\%) with chordates as the most popular focus taxa (40\%). Some form of methodological training for participants is provided by $64.2 \%$ of projects, and the most popular tasks undertaken are field surveys (35.8\%) and reporting of opportunistic sightings (34.2\%). Data quality and participant motivation are among the most common challenges facing projects, but identified strengths include enhanced marine policy, increased scientific knowledge and environmental stewardship. In con-
\end{abstract}

H. S. Earp ( $\square)$

Institute of Biology, Environmental and Rural Sciences,

Aberystwyth University, Aberystwyth, Wales, UK

School of Ocean Sciences, Bangor University, Menai Bridge, Wales, UK

A. Liconti

School of Ocean Sciences, Bangor University,

Menai Bridge, Wales, UK

School of Biological and Marine Sciences, Plymouth University, Plymouth, UK clusion, marine citizen science lies at a crossroads of unresolved challenges, demonstrated successes and unrealized potential. However, should the challenges be addressed, the unique capacity of citizen science to broaden the scope of investigations may be the key to the future of marine research and conservation in times of global change and financial hardship.

\section{Keywords}

Volunteer $\cdot$ Public participation $\cdot$ Community-based monitoring $\cdot$ Environmental policy $\cdot$ Ecological surveying

\subsection{Introduction}

\subsubsection{The History of Citizen Science}

Citizen science, often described as amateur participation in scientific research and monitoring, has emerged as a powerful tool and popular activity in recent decades (Cohn 2008; Kullenberg and Kasperowski 2016; Burgess et al. 2017). However, this phenomenon is not new and extends back to before the professionalization of science, whereby most 'scientists' including Benjamin Franklin (1706-1790), Charles Darwin (1809-1888) and Margaret Gatty (1809-1873) made a living in different professions (Silvertown 2009). Yet, despite the evolution of science as a paid profession in the late nineteenth century, amateurs remained involved in many scientific disciplines such as archaeology, astronomy, meteorology and natural history (Silvertown 2009; Haklay 2015). On the verge of the twentieth century, the first 'citizen science project', the National Audubon Society Christmas Bird Count, was established (Cohn 2008; Bonney et al. 2009). It was, however, another 89 years before the first citation of 'citizen science' to describe the collection of rainwater 
samples by 225 volunteers as part of a National Audubon Society acid-rain awareness-raising campaign (Kerson 1989), and a further 15 years before its inclusion in the Oxford English Dictionary (OED) in 2014. Today, citizen science is widely defined as 'scientific work undertaken by members of the general public, often in collaboration with or under the direction of professional scientists and scientific institutions' (OED Online 2018a). However, as an evolving discipline, a transition from the primarily contributory paradigm whereby participants mainly collect data, to more collaborative and co-created approaches, where they are involved in additional elements of the scientific process has been observed (Bonney et al. 2009; Wiggins and Crowston 2011; Teleki 2012). Today, some citizen scientists work alone or through community-driven projects, as opposed to directly collaborating with scientists (Bonney et al. 2016a; Cigliano and Ballard 2018). Nevertheless, over the past 20 years, citizen science has boomed, with millions of participants from diverse backgrounds becoming involved in projects that have extended in scope from the seafloor to the Milky Way and covered almost everything in between (Foster-Smith and Evans 2003; Bonney et al. 2016b).

\subsubsection{Marine Citizen Science}

Although not as prevalent as their terrestrial counterparts (Roy et al. 2012; Cigliano et al. 2015; Theobald et al. 2015; Garcia-Soto et al. 2017), marine citizen science projects provide a cost-effective means of collecting and analysing extensive data sets across vast spatio-temporal scales, using conventional and new observation and simulation tools (Bonney et al. 2009; Silvertown 2009; Hochachka et al. 2012; Garcia-Soto et al. 2017). Wiggins and Crowston (2011) suggested that citizen science projects fall into five exhaustive groups: (1) action-orientated projects that encourage participation in local issues, for example, collecting and categorizing marine debris (e.g. Marine Conservation Society's Beachwatch available at www.mcsuk.org/beachwatch); (2) conservation projects that promote stewardship and management such as restoring coral reefs (e.g. Rescue a Reef available at sharkresearch.rsmas.miami.edu/donate/ rescue-a-reef); (3) investigation projects that answer a scientific question including monitoring coral reefs (Marshall et al. 2012; Done et al. 2017), cetacean populations (Evans et al. 2008; Tonachella et al. 2012; Bruce et al. 2014; Embling et al. 2015) and invasive species (Delaney et al. 2008); (4) virtual projects that are exclusively ICT-meditated, for example, online photo analysis (e.g. Weddell Seal Count available at www.zooniverse.org/projects/slg0808/weddell-sealcount); and (5) education projects whereby outreach is the primary goal (e.g. the Capturing our Coast 'Beach Babies' survey available at www.capturingourcoast.co.uk/specificinformation/beach-babies).

Thiel et al. (2014) examined 227 peer-reviewed studies involving volunteer-scientist collaborations and showed that developed nations including the United States of America (USA), Australia and the United Kingdom (UK) are hotspots for marine citizen science, with easily accessible areas including intertidal and subtidal regions among the most frequently surveyed environments. However, recent technological developments, often dubbed 'citizen cyberscience', have further elevated the accessibility of citizen science and may in turn alter these trends (Science Communication Unit University of the West of England 2013). These developments have allowed volunteers from around the world to 'virtually' participate in marine research across international borders and in otherwise inaccessible environments (e.g. the deep sea) from the comfort of home. Examples include Seafloor Explorer (available at www.seafloorexplorer.org), where participants analysed over two million images of the seafloor ( $250 \mathrm{~m}$ deep) in order to investigate the distribution of commercially important species such as scallops along the northeast United States continental shelf.

\subsubsection{Citizen Science as a Tool in Research and Conservation}

Despite the broad array of topics, the aims of citizen science projects remain similar: to gather data that answers scientific questions and/or drives policy (Cigliano et al. 2015; Bonney et al. 2016b; Garcia-Soto et al. 2017), to promote environmental awareness and literacy, and to empower citizens and communities (Danielsen et al. 2013; Garcia-Soto et al. 2017). Consequently, it has been suggested that citizen science processes and outcomes warrant acknowledgement as a distinct discipline (Jordan et al. 2015; Burgess et al. 2017; GarciaSoto et al. 2017). Despite being incorporated into an increasing array of scientific literature, proposals and conference submissions (Cigliano and Ballard 2018), and evolving welltested protocols and data validation techniques, citizen science has yet to be fully embraced by the scientific community, and questions remain surrounding best practices and data quality and/or verification (Cohn 2008; Silvertown 2009; Bonney et al. 2014; Burgess et al. 2017). This review builds on research by Thiel et al. (2014) that demonstrated trends across marine citizen science published in peer-reviewed journal articles, in order to highlight the diversity of current marine citizen science projects. This includes projects that have published their data in peer-reviewed journals, as well as those whose primary aims are to provide data that drives management or to educate and engage the public. 'Voluntourism' projects are excluded from our considerations as they primarily constitute "voluntary work typically 
aiming to help others' (OED Online 2018b) as opposed to the 'scientific work' nature of citizen science. The selected marine citizen science projects were examined in order to highlight trends in terms of: geographic locations, focal taxa, participant demographics, tasks undertaken and data directionality (i.e. data publication and storage). Challenges and strengths arising from the review are then presented before suggestions for the future of citizen science in marine research and conservation are made.

\subsection{Methodology}

\subsubsection{Project Selection}

Marine citizen science projects were collated using: (1) Google searches using the keywords 'marine + citizen + science', (2) searches on the citizen science database SciStarter (available at www.scistarter.com) using the keyword 'marine', (3) the Wikipedia citizen science project list (available at www.wikipedia.org/wiki/List_of_citizen_science_projects), (4) social media searches on Facebook using the keywords 'marine + citizen + science', (5) projects mentioned in reviewed literature and (6) personal knowledge. Project websites were consulted, and a project was included in the review when it had a marine focus and involved citizen scientists. In cases where an organization coordinated multiple citizen science projects, each project was included individually (e.g. The Shark Trust coordinates; The Great Eggcase Hunt, Basking Shark Project and Angling Project: Off The Hook, available at www.sharktrust.org/en/citizen_science). In cases where a project organized multiple campaign style activities, the project alone was included (e.g. Capturing our Coast available at www. capturingourcoast.co.uk). A total of 120 projects, covering the majority of oceans, their associated flora and fauna, and several conservation issues met the selection criteria (see Appendix 1 for a list of reviewed projects). Data for each project was collected by combining information available from websites, newsletters, databases and email communications. Core data included lead organization, year of establishment, spatial coverage (i.e. international, regional, etc.), location, focus area/taxa, volunteer training requirement (i.e. written instructions, training programs), activity genre (i.e. fieldwork/online) and tasks undertaken (i.e. sightings, image/recording analysis, etc.). When available, information on the number of surveys undertaken by citizen scientists, data validation techniques (i.e. data quality checking), data directionality (i.e. storage location) and number of peer-reviewed scientific publications using the projects data set was also recorded.

\subsection{Identified Trends Across Marine Citizen Science Projects}

\subsubsection{Geographic Location}

\subsubsection{Spatial Coverage}

The reviewed projects occurred across multiple geographical scales, extending from local and regional levels $(4.2 \%)$ to international and global coverage $(42.5 \%)$. The majority of projects acted at national levels $(53.3 \%)$ and spanned nine locations (Fig. 1.1), with the most being located in the USA (43.8\%), followed by the UK (27.4\%) and Australia (11\%). A trend towards greater project abundances in developed

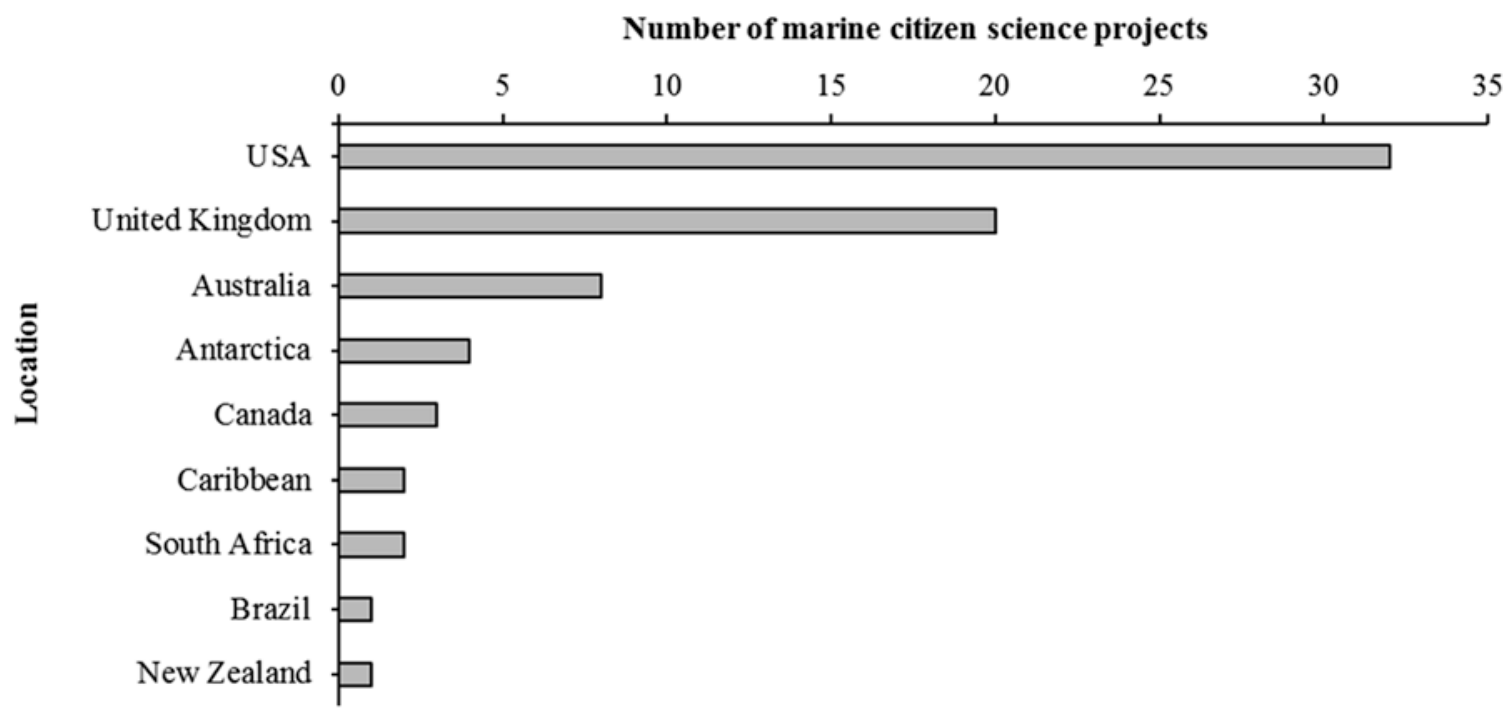

Fig. 1.1 Number of reviewed marine citizen science projects per location, excluding those operating on international $(\mathrm{n}=10)$ or global $(\mathrm{n}=37)$ scales 
nations was observed, with only $6.8 \%$ of projects occurring in nations with developing economies (as defined by the United Nations Conference on Trade and Development (UNCTADstat 2018)), for example, Brazil and South Africa. A similar trend was reported by Thiel et al. (2014), although this may be attributed, in part, to the fact that projects incorporated in these reviews were selected based on their journal publications and websites, and consequently projects using other communication strategies to engage with citizen scientists (e.g. local community groups that may be more abundant in developing nations) are excluded.

\subsubsection{Environmental Coverage}

The most commonly investigated environment was the coastal ocean (depth $<200 \mathrm{~m})(49.2 \%)$, closely followed by easily accessible coastline regions (34.2\%) (Fig. 1.2). Although further divisions into zones such as the supralittoral, intertidal, subtidal, continental shelf and oceanic environments (similar to Thiel et al. 2014) were beyond the scope of this review, this information could provide a greater insight into hotspot environments for marine citizen science, as well as those with capacity for development. Interestingly, studies specifically focused on environments known for their roles in supporting ecosystem functions and services, including mangrove and kelp forests, seagrass meadows and wetlands, were limited (5\% in total), demonstrating potential opportunities for expansion of citizen science in these environments. An exception was coral reefs that were the focus of investigation in $8.3 \%$ of projects, potentially due to their charismatic appeal, exotic location, alongside the relative ease of conducting research involving SCUBA diving in these environments, and the higher volume of visitors as potential citizen science participants (relative to colder oceanic environments).

The deep sea remained the least studied environment with only one project, Digital Fishers (available at www.oceannetworks.ca), focusing their investigations on the organisms inhabiting this remote and often inaccessible region. However, inaccessibility may not be the only reason for the lack of projects concerning this environment, as limited scientific knowledge and expensive technologies may also be factors. Despite large deep-sea video databases being available online (National Oceanic \& Atmospheric Administration Ocean Explorer available at www.oceanexplorer.noaa.gov; Monterey Bay Aquarium Research Institute available at www.mbari.org; Japan Agency for Marine-Earth Science \& Technology e-library of deep-sea images available at www. godac.jamstec.go.jp), the identification of deep-sea organisms remains complex and thus must be conducted by experts in this field. However, in order to enhance the identification process (i.e. make it quicker and easier), software is currently under development that can automatically identify deep-sea species, and in the case of Digital Fishers, citizen scientists are contributing to the development of this software by 'educating' it to count and identify different taxa (Ocean Networks Canada 2018).

The majority of reviewed projects $(25.8 \%)$ focused on multiple taxa ('Diverse Taxa') (Table 1.1), through investigations on the intertidal or subtidal or on invasive species and planktonic communities. However, among the most popular individual taxa were the so-called charismatic megafauna, including marine mammals (15\%), seabirds (8.3\%) and

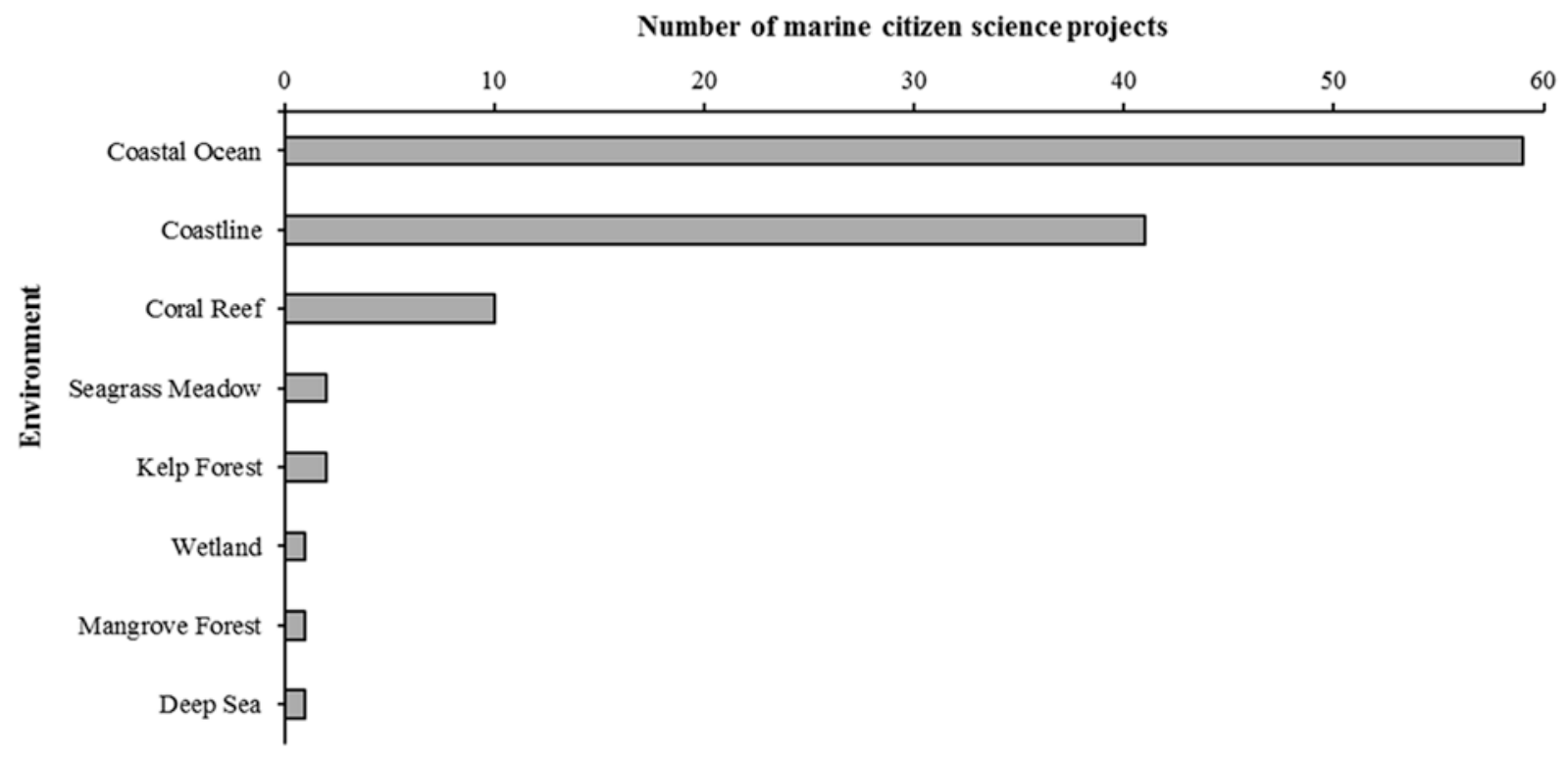

Fig. 1.2 Number of reviewed marine citizen science projects per environment, excluding those that focused on multiple environments (e.g. Redmap, available at www.redmap.org.au) $(\mathrm{n}=3)$ 
Table 1.1 Focus taxa of the reviewed marine citizen science projects, excluding those that focused on oceanography or pollution $(n=18)$. Diverse taxa includes projects focusing intertidal and subtidal flora and fauna, alongside those that focus on multiple invasive or planktonic taxa

\begin{tabular}{l|l|l}
\hline \multicolumn{2}{l}{ Taxa } & Number of projects \\
\hline \multirow{3}{*}{ Chordata } & Mammalia & 18 \\
\cline { 2 - 3 } & Aves & 10 \\
\cline { 2 - 3 } & Chondrichthyes & 9 \\
\cline { 2 - 3 } & Osteichthyes & 8 \\
\cline { 2 - 3 } & Actinopterygii & 1 \\
\cline { 2 - 3 } & Reptilia & 1 \\
\cline { 2 - 3 } & Diverse taxa & 1 \\
\hline Cnidaria & Anthozoa & 8 \\
\hline Arthropoda & Scyphozoa & 1 \\
\hline Plantae & Crustacea & 6 \\
\hline Heterokontophyta & Diverse taxa & 1 \\
\hline Echinodermata & Angiosperma & 4 \\
\hline Mollusca & Phaeophyceae & 3 \\
\hline Diverse Taxa & Echinoidea & 1 \\
\hline
\end{tabular}

sharks/rays (7.5\%), which are often considered more newsworthy compared to projects focusing on seaweeds or plankton (Stafford et al. 2010). Surprisingly, sea turtles (also considered charismatic megafauna) were the focus of only one project (Seaturtle.org available at www.seaturtle.org), yet were highly popular among voluntourism projects (e.g. Sea Turtle Conservation available at www.volunteeringsolutions.com, www.frontier.ac.uk and www.gvi.co.uk; SEE Turtles available at www.seeturtles.org). In addition to the popularity of charismatic megafauna, charismatic sessile organisms, such as corals, are frequently investigated by marine citizen science projects, accounting for $6.6 \%$ of projects in this review. Despite the popularity of projects involving charismatic taxa, studies focusing on lesser charismatic organisms such as plankton (e.g. FjordPhyto available at www.fjordphyto.wordpress.com; Secchi Disk available at www.secchidisk.org) are growing in popularity, with estimates showing $\sim 110,900$ volunteers are engaged in the counting and identification of plankton in the Mediterranean Sea and California currents through Plankton Portal (www. planktonportal.org).

\subsubsection{Participant Demographics}

\subsubsection{Participant Recruitment}

At present, there is no quantification of the number of citizen scientists actively involved in scientific research. However, as it often entails limited/no cost, the number is likely to exceed that of voluntourists (estimated at 10 million people per annum by McGehee 2014). Citizen scientists involved in marine research descend from a diverse array of backgrounds and may have no formal training or qualifications in marinerelated subjects (Thiel et al. 2014). Participant recruitment often occurs through collaborations with other established nature organizations including conservation groups and ocean water sport centres. These recreational users of the marine environment, especially SCUBA divers (Martin et al. 2016), often have enhanced interests in marine life and its preservation and are consequently attracted to opportunities whereby they can expand their knowledge base and participate in research (Campbell and Smith 2006; Cohn 2008). More recently, online tools (i.e. project websites and social media) have provided a low-effort method of recruiting both on- and off-site participants. This is partially due to the fact that those with an interest in nature conservation are usually connected with other like-minded people and/or groups online, and consequently a positive loop of information sharing is generated that benefits both citizen science outreach and recruitment.

The majority of reviewed projects are open to participants of any age, although several were noted to exhibit a preference for adult participants (i.e. aged 18 and over); however, this is often due to protocol complexity (see sect. 3.3 for a review). In cases where the protocol requires species identification, adult participants are often designated as final decisionmakers, although younger participants may assist under supervision (e.g. Capturing our Coast available at www.capturingourcoast.co.uk). In the case of projects that involve SCUBA diving, only participants that meet the minimum requirements (e.g. certification and/or experience level) are permitted to partake. However, some variation among minimum requirements is exhibited, for example, to certify as a Reef Check Ecodiver, participants must be comfortable with the use of a mask, snorkel and fins or be a certified SCUBA diver (Reef Check 2018), while the requirements to become a Seasearch Observer include being certified as a PADI Advanced Open Water Diver (or equivalent) and having $>20$ dives, of which $\geq 10$ should be in temperate waters (Seasearch 2018). Despite some background experience being required in these instances for safety, none of the reviewed projects required participants to have any educational background, as they become trained and therefore specialists in the task required (Hobson 2000). Furthermore, some projects allow participant development to a level whereby they can become project organizers, coordinators, or even lead authors in scientific publications and/or identification guides (see Bowen et al. 2011 for an example of an identification guide authored by citizen scientists). An example includes Seasearch (available at www.seasearch.org.uk) that coordinates general surveys that all participants may undertake, as well as a 'surveyor' level survey for participants that undertake advanced training, and 'specialist projects' created by marine biology experts and experienced volunteers. The latter may 
involve additional training but in some cases are open to experienced divers that have no previous Seasearch experience (Bunker et al. 2017; Kay and Dipper 2018). This demonstrates how well-designed and long-term projects can satisfy participants from varied backgrounds and allow for significant participant development.

\subsubsection{Participant Training}

Basic training of participants occurs across the majority of marine citizen science projects and extends from written instructions, to two-three-day training programs, especially in projects involving specific methodological techniques/ protocols (Thiel et al. 2014). Within this review, 77 projects provided some form of participant training, of which $29.9 \%$ involved brief instructions, 53.2\% involved basic training (i.e. an event where an expert introduced the protocol to be employed) and $16.9 \%$ included a $\geq$ one-day training course. Training of participants involved in projects that use simple protocols (i.e. count or presence/absence surveys) (see sect. 3.3 for a review) primarily occurs through basic written instructions on data sheets and at times video tutorials (Bravo et al. 2009; Ribic et al. 2011). However, in projects that require more complex protocols (i.e. quadrat or transect surveys) and species identification, participants often attend a compulsory $\geq$ one-day training course, and it was noted that many of these projects often also involve SCUBA diving. Participant capabilities are usually assessed throughout the training, although only six projects explicitly stated that they verified participant capabilities. In addition, complex survey techniques often require additional scientific equipment (e.g. quadrats, transects, diving slates, identification guides, etc.) that are costly, resulting in some projects (e.g. Reef Check California, Mediterranean Sea and Tropical available at www.reefcheck.org) requesting a fee to cover the cost of the training and tools. Although this may limit the project's accessibility, it also ensures training quality and often enhances the recruitment of highly motivated participants. Citizen scientists contributing financially to projects might consider it an investment, and they may in turn be more likely to continue participating. However, this theory has yet to be tested explicitly and represents the scope for future research. Despite the multiple benefits of training, $25.8 \%$ of projects required no training, and the majority of these are reliant on incidental sightings (i.e. stranded animals or marine debris) (McGovern et al. 2016). In the case of stranded animals, citizen scientists report the sighting, and professionals are then required for the subsequent removal, identification and autopsy (Avens et al. 2009).

For the most part, the projects considered in this review allow participants to conduct research without professional supervision. Consequently, full explanatory training is key to ensuring the collection of scientifically sound and highquality data (see sect. 3.4 for a review), and the length of the training is somewhat correlated to the complexity of the protocol employed. Some projects further engage with participants through the organization of additional events and courses in order to maintain project engagement and allow for upskilling. An example of this is Capturing our Coast (available at www.capturingourcoast.co.uk) that organizes regular refresher events for trained participants to maintain their survey/identification skills and to enhance data quality, alongside engagement events such as 'Wine and Science' where participants are invited to talks by guest speakers that cover a range of marine science disciplines. Beyond training, many projects communicate with their participants through their websites, newsletters and social media in order to keep them up-to-date with the project progress and encourage further participation. In addition, 'group sourced identification forums' on websites and social media are growing in popularity and may assist in participant engagement and increase the accuracy of the citizen-collected data (Chamberlain 2018). Informal participant feedback has suggested that online engagement strategies are becoming increasingly important components of marine citizen science projects (E. Morris-Webb, personal communication). However, there is currently a lack of systematic reviews on the role of outreach tools in the retention of volunteers highlighting the potential for future research in this area.

\subsubsection{Tasks Undertaken}

In order for citizen science projects to investigate the diverse array of habitats and species mentioned previously, a heterogeneous range of methodologies are employed. Each project must use methods that are appropriate to the field of enquiry but that are within the capabilities of the participants recruited (Worthington et al. 2012). Among the most popular are field surveys $(35.8 \%)$ and reporting of opportunistic sightings $(34.2 \%)$ (Fig. 1.3), which aligns with the findings of Thiel et al. (2014). Field surveys primarily involve searches for both live (e.g. Reef Check Tropical available at www.reefcheck.org/tropical/overview) and deceased organisms (e.g. Beach COMBERS, available at www.mlml.calstate.edu/ beachcombers), as well as ecological phenomena (e.g. Bleach Patrol available at www.ldeo.columbia.edu/bleachpatrol), during predefined time periods or within predefined areas such as transects and quadrats. Surveys generally require citizen scientists to report findings of abundance or presence/absence, although in some cases, parameters uniquely designed for that project are requested, for example, the reef coloration requested in the CoralWatch bleach- 


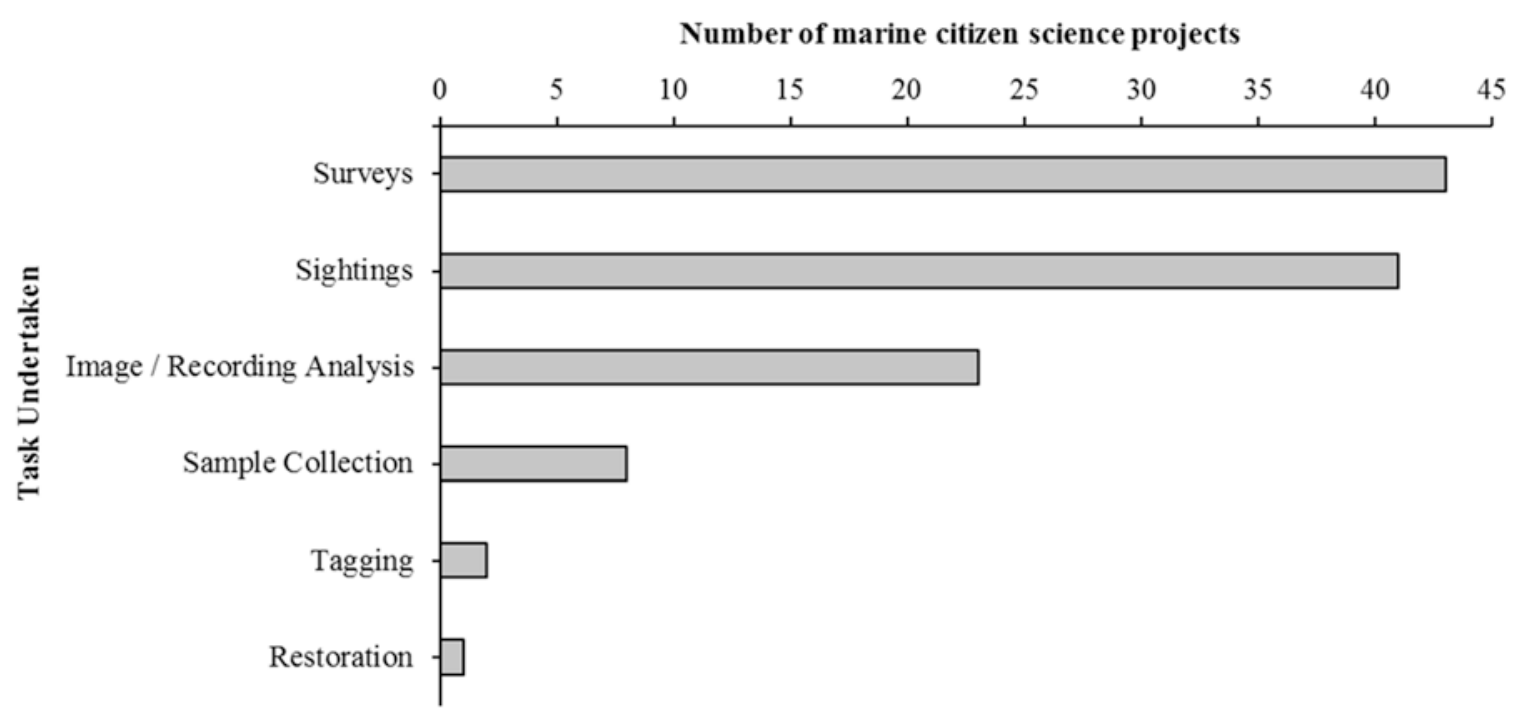

Fig. 1.3 Number of reviewed marine citizen science projects per primary tasks undertaken, excluding those that involved several tasks $(\mathrm{n}=2)$

ing protocol (available at www.coralwatch.org). Other surveys involve more novel methods, such as divers4oceanography (available at www.divers4oceanography.org) that asks SCUBA divers to report ocean temperatures recorded on their dive computers, and Smartfin (available at www. smartfin.org) that has designed a surfboard fin with sensors that allows surfers to collect real-time ocean parameters including temperature, location and wave characteristics (sensors that measure salinity, $\mathrm{pH}$, dissolved oxygen and chlorophyll are under development). Surveying remains a key methodology of marine citizen science projects due to its cost-effectiveness, relative ease of implementation and ability to generate data across large spatio-temporal scales. Opportunistic sightings again allow data to be generated across vast scales and are at times a more time- and effortefficient method compared to quadrat and transect surveys (Wiggins and Crowston 2011; Cox et al. 2012, 2015); although for the most part, they are employed by projects focusing on marine mammals, jellyfish and marine debris (including both field and online projects).

Technological developments have allowed an increasing number of projects to incorporate online citizen scientists to analyse vast data sets of images and recordings (19.1\%), often through web portals such as Zooniverse. The popularity of this method lies in the fact that its only limitation is the often time-consuming preparation of the photos prior to being uploaded online. Finally, a combination of advanced technology and that fact that they are often focused on specific target organisms may explain why tagging (i.e. catch, tag and release of organisms) and restoration (i.e. environmental regeneration) were among the least used methodologies (1.6\% and $0.8 \%$, respectively) (Fig. 1.3).

\subsubsection{Data Directionality}

\subsubsection{Data Quality}

Citizen science strives to meet the same credibility standards as academic research and industry; however, it is often subject to limited resources and consequently faces trade-offs between data quantity and quality, protocol standardization and discrepancies in skills and expectations of participants and project facilitators/scientists (Robertson et al. 2010; Tulloch et al. 2013). To maintain data quality, some projects statistically compare results reported by citizen scientists to those of professional scientists as a means of data validation (Bell 2007; Worthington et al. 2012; Holt et al. 2013; Bird et al. 2014; Thiel et al. 2014; Earp et al. 2018b). Within this review, $19.2 \%$ of projects were found to validate their data in some way, which is much lower than the $55.1 \%$ reported by Thiel et al. (2014) in a similar investigation. However, an increasing body of research has shown that data collected by citizen scientists meets, or surpasses accepted quality standards, or detects important ecological trends (Cox et al. 2012; Forrester et al. 2015; Kosmala et al. 2016; Schläppy et al. 2017). In the study of Delaney et al. (2008), the accuracy of volunteers in identifying native and invasive crabs was assessed and found to be between 80 and $95 \%$ accurate for school children and even greater for those with a university education, suggesting that demographic variables such as age and educational background may be important drivers of data quality. As a result, choosing a research topic to suit the target participants is key to the success of a citizen science project. In other studies, increasing experience level (Jiguet 2009) and training of participants (Edgar and StuartSmith 2009) (see sect. 3.2.2 for a review) were shown to 
positively correlate with data quality. In other cases, citizen science data has been shown to demonstrate bias or inaccuracies (Courter et al. 2013; Forrester et al. 2015; van der Velde et al. 2017), but this can be minimized in data summaries by examining broader-scale trends (e.g. family level rather than species level) (Fore et al. 2001; Gouraguine et al. 2019) or excluding data from participants that differed substantially to data collected by scientists (Culver et al. 2010). Irrespectively, perceptions on data quality remain a key factor influencing the publication of citizen science data (Schläppy et al. 2017).

\subsubsection{Data Publication}

In recent years, an increasing number of peer-reviewed journal articles have focused on marine citizen science with many incorporating participant-collected data. This was the case for a minimum of 44 of the 120 reviewed projects that have contributed data to at least 1483 peer-reviewed journal articles. The majority of these publications (54\%) were in relation to chordates (Fig. 1.4), of which $70 \%$ focused on marine mammals followed by seabirds (15.6\%). Interestingly, only $5.2 \%$ of chordate publications focused on groups such as sharks and rays. Projects concentrating on diverse taxa were also highly likely to contribute to publications (29.1\%), whereas $<2 \%$ of publications focused on marine pollution.

Despite marine mammals and pollution being the focus of comparable project numbers, the publication frequency of marine mammal data is over 30 times greater than that of marine pollution. This discrepancy may be due to the fact that pollution is a relatively new trend in marine citi- zen science, whereas the majority of marine mammal projects are well established and commenced prior to 2008. Although the trend towards pollution-based studies has allowed for vast data sets to be generated in seemingly short time periods, the number of investigations (i.e. surveys) was shown to have less of an influence on publication frequency compared to project duration (Fig. 1.5a). Project durations vary from days to decades (Thiel et al. 2014), and of the projects that state their start date $(n=103)$, the greatest percentage $(24.3 \%)$ are currently between 2 and 5 years in duration. Despite a limited correlation between project duration and publication frequency (Fig. 1.5b), short projects have a demonstrated capacity to be published, for example, in the 2-day 'bioblitz' undertaken by Cohen et al. (2011) in Sitka (Alaska), where citizen scientists collected data that confirmed a $1000 \mathrm{~km}$ northward extension of the colonial tunicate Didemnum vexillum (Sundlov et al. 2016).

\subsubsection{Policy Development}

It is important to note that peer-reviewed journal articles are not the only outlet for marine citizen science data, and in some cases, especially in terms of marine pollution, the data collected is more valuable for aspects such as informing policy or driving management (Newman et al. 2015; Burgess et al. 2017). Marine legislation is often underpinned by evidence from large data sets, and citizen science provides a cost-effective method for their generation (Crabbe 2012; Hyder et al. 2015). The importance of marine citizen science in delivering evidence to support decision-making in marine

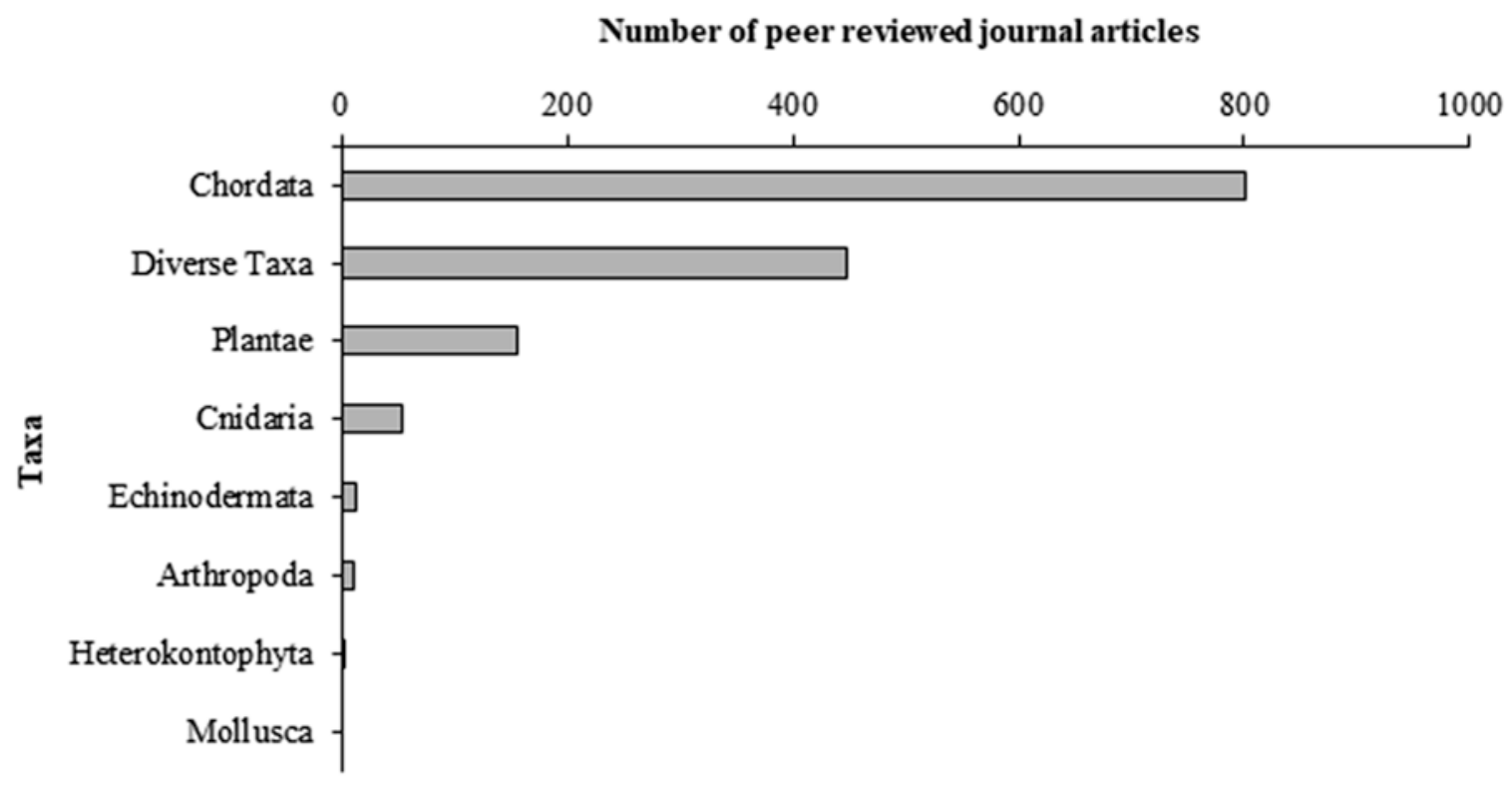

Fig. 1.4 Number of peer-reviewed journal articles $(n=1483)$ per focus taxa published by reviewed marine citizen science projects, excluding those that focus on oceanography or pollution $(n=18)$ 
a)

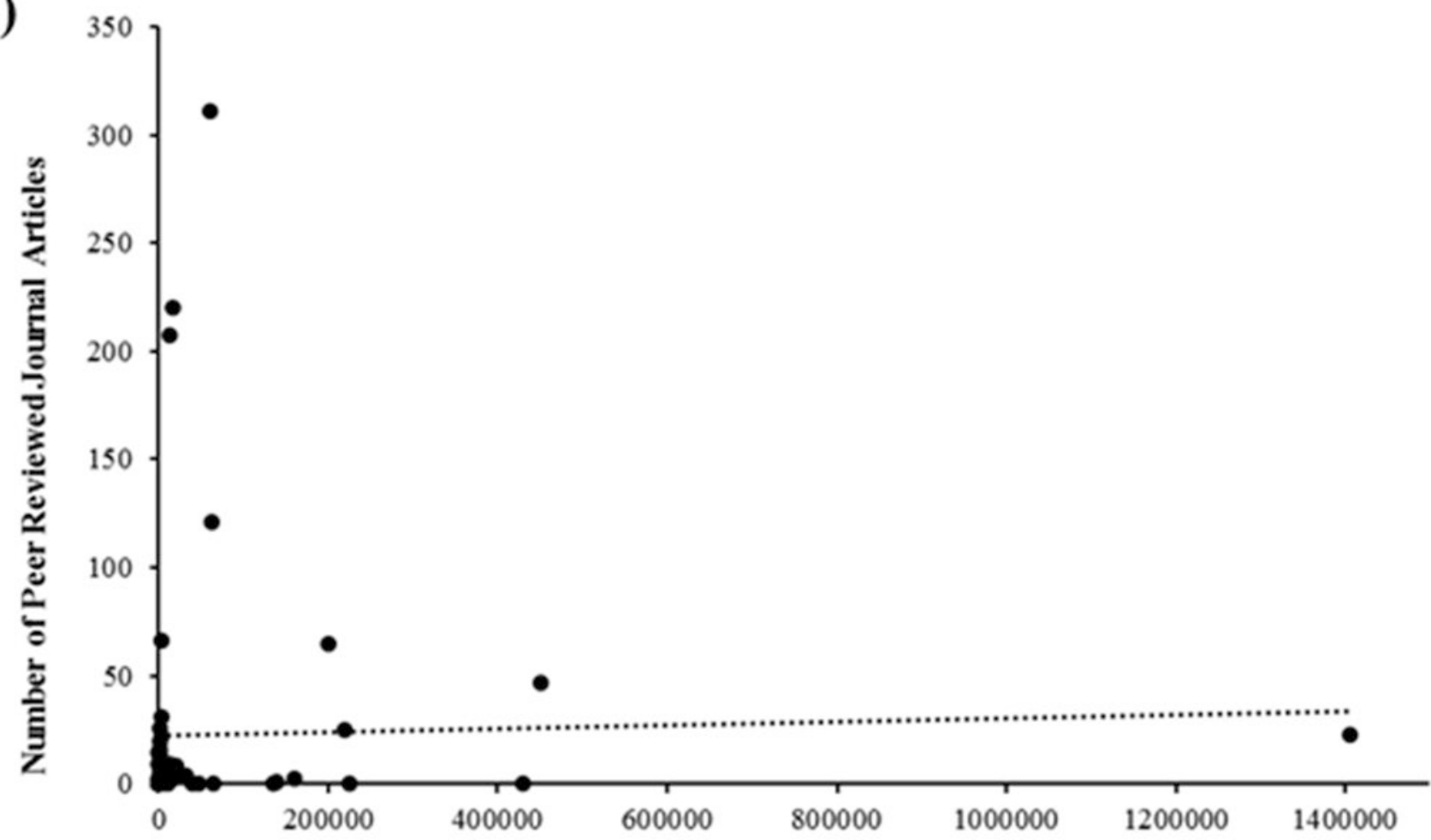

Number of Investigations

b)

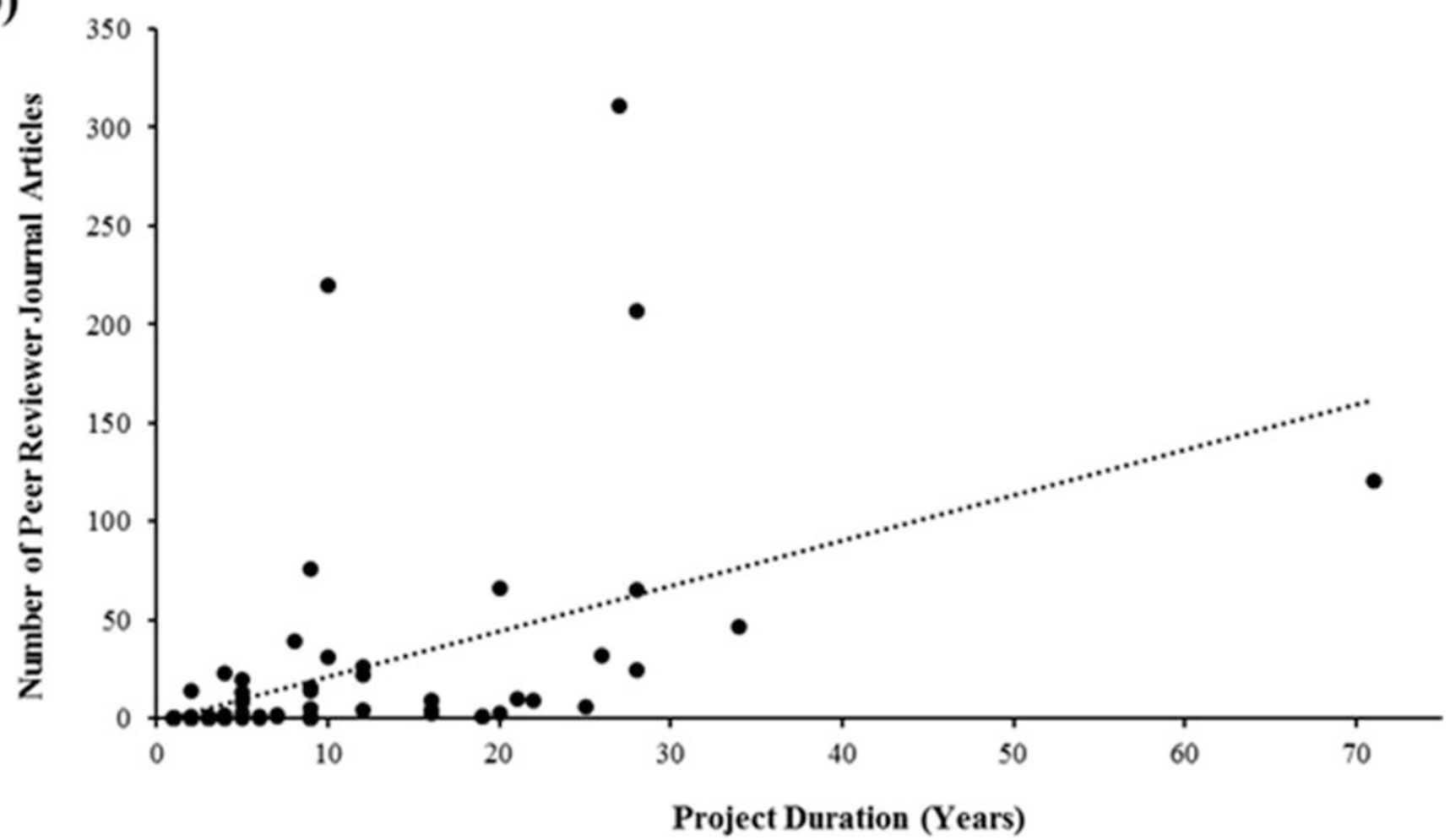

Fig. 1.5 Number of peer-reviewed journal articles published by reviewed marine citizen science projects $(n=1483)$ vs. number of project investigations (i.e. surveys) (a) and project duration (b) 
Table 1.2 The primary policy area underpinned by reviewed marine citizen science projects and the total number of publications generated by projects in each of these areas

\begin{tabular}{|c|c|c|c|}
\hline Policy & Area & $\begin{array}{l}\text { Number of } \\
\text { projects }\end{array}$ & $\begin{array}{l}\text { Number of } \\
\text { publications }\end{array}$ \\
\hline \multirow[t]{6}{*}{ Biodiversity } & Species distribution & 43 & 790 \\
\hline & MPA designation & 7 & 166 \\
\hline & $\begin{array}{l}\text { Invasive non-native } \\
\text { species }\end{array}$ & 6 & 0 \\
\hline & Stranding & 4 & 211 \\
\hline & $\begin{array}{l}\text { Threatened and rare } \\
\text { species }\end{array}$ & 4 & 42 \\
\hline & $\begin{array}{l}\text { Other biological } \\
\text { research }\end{array}$ & 31 & 184 \\
\hline \multirow[t]{2}{*}{$\begin{array}{l}\text { Physical } \\
\text { environment }\end{array}$} & $\begin{array}{l}\text { Oceanographical } \\
\text { research }\end{array}$ & 4 & 2 \\
\hline & Climate change & 2 & 0 \\
\hline \multirow[t]{2}{*}{ Pollution } & Marine debris & 10 & 15 \\
\hline & Water quality & 4 & 15 \\
\hline $\begin{array}{l}\text { Resource } \\
\text { management }\end{array}$ & Fisheries & 5 & 27 \\
\hline
\end{tabular}

legislation was reviewed by Hyder et al. (2015), who classified four marine policy areas (biodiversity, physical environment, pollution and resource management) in which citizen science had played a valuable role. Within our review, the majority of projects (79.2\%) were found to provide evidence underpinning biodiversity conservation policies (Table 1.2). Within this policy area, $>40 \%$ of projects investigated questions regarding species distribution, which was supported by findings from a study by Hyder et al. (2015). Other popular policy areas underpinned by the reviewed projects were: biological research (25.8\%), marine debris surveying (8.3\%), marine protected area (MPA) designation (5.8\%) and invasive species tracking (5\%) (Table 1.2).

\subsubsection{Data Storage}

Although the use of citizen science data varies, projects are encouraged to make their data publicly accessible, yet in this review, less than $10 \%$ of projects stored their data on a repository (e.g. NBN Atlas available at www.nbnatlas.org). In particular, all species survey data from reviewed citizen science projects in the UK is stored on NBN Atlas, which is accessible to the public and government for a range of purposes, although some data limitations exist regarding commercially sensitive/overexploited species. The majority of reviewed projects instead made their data available through the project website $(50.8 \%)$, although $40 \%$ of projects kept their data private or failed to disclose its location.

\subsection{Species Distribution}

The long-term observational data sets generated by citizen science projects, which often extend beyond timescales of standard research programs (i.e. two-three years), are also of exceptional value in addressing questions regarding the spatio-temporal distribution of marine organisms (Ponti et al. 2011b; Mieszkowska et al. 2014). More recently these data sets have become important in assessing the response of organisms to climate change (Southward et al. 2005; Mieszkowska et al. 2014). Climate change can induce socalled shifts in marine species distributions, either towards more favourable seawater temperatures or because of trophic mismatches resulting from changes in prey phenology (Visser and Both 2005; Cheung et al. 2009). Mieszkowska et al. (2014) demonstrated some of the fastest geographic range shifts in marine species in 50 years using citizen science data collected as part of the Marine Biodiversity and Climate Change (MarClim) project. Lusitanian species, including Phorcus (previously Osilinus) lineatus and Steromphala (previously Gibbula) umbilicalis (topshells), Chthamalus montagui and Perforatus perforatus (barnacles), as well as the limpet Patella depressa and the macroalga Bifurcaria bifurcata, extended their range poleward, whilst Boreal species, such as the barnacle Semibalanus balanoides and the kelp Alaria esculenta, were shown to be important indicator species that fluctuate in abundance in response to periods of warming and cooling (Mieszkowska et al. 2014). Although only two projects in this review investigated physical components of climate change (i.e. changes in temperatures, $\mathrm{pH}$ and storm frequency), numerous projects (35.8\%) addressed questions regarding species distributions with several of these providing information important for climate change studies (e.g. information on coral bleaching that results from climatic change).

\subsection{Invasive Non-Native Species}

Marine citizen science is not only a powerful tool in monitoring the distribution of native species but also the arrival and encroachment of invasive non-native species (Delaney et al. 2008; Parr and Sewell 2017), whose impacts on native ecosystems remain poorly understood (Ruiz et al. 1997). These species can go undetected for extended periods of time (i.e. years) (Geller et al. 1997; Lohrer 2001), meaning their subsequent eradication may be difficult, in part because of large population sizes (Bax et al. 2001). Consequently, monitoring for invasive species is of primary importance so that early eradication can be conducted (Delaney et al. 2008). In the USA, the Citizen Science Initiative: Marine Invasive Species Monitoring Organization (www.InvasiveTracers.com) used 190 groups of participants to survey 52 sites for a species of introduced Asian shore crab (Hemigrapsus sanguineus), previously known only to be present in Moores Harbour. They reported a notable expansion of the range of $H$. sanguineus, with one specimen being reported $60 \mathrm{~km}$ northeast of Moores Harbour (Delaney et al. 2008). Some invasive species are 
not only detrimental to native ecosystems, but also to local economies, for example, the carpet sea squirt (Didemnum vexillum), which was discovered in the UK for the first time by citizen scientists in a study conducted by Cohen et al. (2011). D. vexillum is detrimental to shellfish aquaculture with high abundances resulting in increased labour costs and reduced product value (Watson et al. 2009; Adams et al. 2011). Knowing the origin and arrival location of invasive species is very important to model their potential dispersion pathways, allow for early detection and in turn limit further colonization of new areas (Ricciardi et al. 2000). The spatio-temporal scale at which citizen science operates is therefore of exceptional value to invasive species monitoring and benefits both scientific research and industry. Although several of the reviewed projects (e.g. Capturing our Coast available at www.capturingourcoast. co.uk, Seasearch available at www.seasearch.org.uk and Reef Check Mediterranean Sea available at www.reefcheckmed.org) have trained volunteers to report sightings of non-native species, they were the primary focus of only $5 \%$ of reviewed projects (Table 1.2), therefore demonstrating scope for significant expansion of marine citizen science in this area.

\subsection{Marine Debris}

As part of an action to tackle a widespread and growing issue, citizen scientists are helping to investigate marine debris by contributing to vast global data sets that form the basis of both political decisions and conservation policies (Ryan et al. 2009; Eriksen et al. 2014; Hidalgo-Ruz and Thiel 2013, 2015; Nelms et al. 2017). Although this policy area was underpinned by only $8.3 \%$ of projects within this review (Table 1.2), it has grown considerably in the past decade, with more citizens sharing responsibility for the issue and contributing to projects aiming to provide solutions (Hidalgo-Ruz and Thiel 2015; Nelms et al. 2017). These projects often involve simple beach clean-ups that provide information on the distribution and abundance of marine debris items (Ribic 1998; Martin 2013). Because of the simplicity of the protocols, several citizen science projects underpinning different areas of policy (i.e. biodiversity policies such as species distribution and stranding) have organized events to tackle marine debris issues and contributed to litter recording databases. In the $\mathrm{UK}$, citizen scientists reported and collected over 10,866 plastic bottles as part of the Marine Conservation Society Wild Bottle Sighting campaign (www.mcsuk.org/bottlesightings). The awareness raised and evidence collected through this, and other similar campaigns (OSPAR 2010; Van Franeker et al. 2011), were key to the decision of the UK government to develop a Deposit Return System for plastic bottles and aluminium cans as part of a plan to eliminate single-use plastic by 2042 (official press release available at www.gov.uk/government/ news/deposit-return-scheme-in-fight-against-plastic).

\subsection{Marine Protected Areas}

One method to protect and promote biodiversity is the designation of marine protected areas (MPAs) and Marine Conservation Zones (MCZs); however to do this, patterns of species distributions across vast spatio-temporal scales (such as those covered by citizen science/scientists) are required (Dickinson et al. 2010; Cerrano et al. 2012; Crabbe 2012; Markantonatou et al. 2013; Branchini et al. 2015; Jarvis et al. 2015; Cerrano et al. 2017). Additionally, marine citizen science is also an effective tool for monitoring MPAs that is essential to support adequate management and to fulfil the requirements of the European Marine Strategy Framework Directive (Directive 2008/56/EC) (Ponti et al. 2011a; Cerrano et al. 2017; Turicchia et al. 2017). This review found that $5.8 \%$ of projects provided data that underpins MPA designation and/or monitoring (Table 1.2). Despite this low percentage, the majority of these projects were found to operate over extensive geographical ranges (e.g. Reef Check available at www.reefcheck.org; eOcean available at www.eoceans.co; SubseaObservers available at www.subseaobservers.com). Since its establishment in 1996, Reef Check data has contributed to the establishment and monitoring of several MPAs in regions with limited funding for conservation policies (Cerrano et al. 2012), and in the UK, the Seasearch data set that extends back to 1984 has contributed to the designation of $38 \mathrm{MCZs}$ and several other MPAs including Lamlash Bay No-Take Zone (Seasearch 2018).

\subsection{Challenges and Strengths of Marine Citizen Science}

\subsubsection{Challenges}

The rapid expansion of marine citizen science, coupled with advancing possibilities and limited funding means, at present, limited guidelines for good practice are in place, and instead many facilitators are learning on the job (Silvertown 2009). Consequently, many projects face challenges, usually in the form of participant motivation and/or data issues.

\subsubsection{Participant Motivation}

At the organizational level, motivation is one of the most commonly referenced challenges facing citizen science (Conrad and Daoust 2008; Conrad and Hilchey 2011; Rotman et al. 2012), and it comes in two forms: (1) motivating outsiders to sign-up and begin participating and (2) motivating participants to continue or expand their participation 
(Prestopnik and Crowston 2011; Rotman et al. 2012). To motivate participants to sign up, some projects focus specifically on either charismatic organisms (Bear 2016; GarciaSoto et al. 2017) or accessible environments (Garcia-Soto et al. 2017), or incorporate an activity (e.g. SCUBA diving) into the protocol to engage participants who readily participate in this activity already (e.g. Seasearch available at www. seasearch.org.uk). However, these strategies generate issues including a data bias towards charismatic species and accessible nearshore environments that may be of limited ecologi$\mathrm{cal} / \mathrm{scientific} \mathrm{relevance,} \mathrm{or} \mathrm{if} \mathrm{SCUBA} \mathrm{diving} \mathrm{is} \mathrm{required,} \mathrm{the}$ project may become cost and/or experience prohibitive to certain participants. An often-unaddressed issue of citizen science is accessibility, especially for participants with impairments. For the most part, projects involve either a physical task in a somewhat hazardous (i.e. slippy) environment, a highly skilful and intense activity (e.g. SCUBA diving), or recording on small data sheets. Consequently, participants with impairments may be limited to online marine citizen science projects, unless a protocol can be adapted to suit their needs.

Motivating participants to continue or expand their participation is often a greater challenge, especially when the project involves reporting 'zero data', which may be of significant scientific importance, but it is often disengaging and might result in declines in participation (Bear 2016). One solution to maintain engagement that is also used to motivate sign-ups and initial participation is gamification (Prestopnik and Crowston 2011) and/or incentivization of the protocol (e.g. the 'Top Trumps' format of the Capturing our Coast 'Beach Babies' survey, available at www.capturingourcoast. co.uk/specific-information/beach-babies). For participants, the more fun, or the greater the benefit they receive from completing the work, the more likely they are to participate (Prestopnik and Crowston 2011). In addition, feedback to participants is of exceptional importance (Bonney et al. 2009; Silvertown 2009) and has been shown to increase and/ or maintain participation by demonstrating the value of their contribution (Rotman et al. 2012). Research from Thiel et al. (2014) supports this view, stating that public recognition of participant effort is a significant motivator for participation but that factors including personal satisfaction (i.e. wellbeing impact of developing social connections and being outdoors) and development of a skill base (i.e. greater understanding of the scientific processes) are also important motivators.

\subsubsection{Data Concerns}

Another obstacle facing citizen science is perceptions regarding data quality (see sect. 3.4 for a review), despite several studies demonstrating that the data meets accepted quality standards (Cox et al. 2012; Forrester et al. 2015; Kosmala et al. 2016; Schläppy et al. 2017). These concerns often relate but are not limited to a lack of attention to project design and standardized data verification methods, limited participant training and sampling biases (Conrad and Hilchey 2011; Burgess et al. 2017). Riesch and Potter (2014) postulated that a lack of use of citizen science data in academia may stem from the belief of some scientists that the data would not be well received by their peers. In terms of policy development, the United States Congress excluded volunteer collected data from their National Biological Survey over concerns that it would be biased based on environmentalist agendas (Root and Alpert 1994). To address the issue of data perceptions, Burgess et al. (2017) suggest greater transparency and availability of methods and data attributes that will hopefully result from the generation of good practice guidelines and toolkits for citizen science (Silvertown 2009). However, despite the shortcomings, many benefits of marine citizen science have been documented. For this reason, the development of a standard 'impact assessment', to assess survey and data verification methods, as well as scientific and socio-psychological benefits would be highly beneficial to marine citizen science projects.

\subsubsection{Strengths}

The strengths of citizen science have been demonstrated to extend across scientific, social and economic boundaries, as well as underpinning several areas of marine policy (see sect. 1.3.4.3) (Delaney et al. 2008; Crabbe 2012; Mieszkowska et al. 2014; Hidalgo-Ruz and Thiel 2015; Hyder et al. 2015; Turicchia et al. 2015; Parr and Sewell 2017).

\subsubsection{The Many Eyes Hypothesis}

The 'many eyes hypothesis' has been used to describe the efficiency of marine citizen science in generating data across vast spatio-temporal scales and across multiple taxa (Hochachka et al. 1999; Dickinson et al. 2012; Thomas et al. 2017). This hypothesis, in the case of animal aggregations, shows a larger group size has extended individual feeding times and an increased likelihood of detecting predators compared to smaller groups (Lima 1995). When applied to citizen science, it demonstrates that a network of citizen scientists with clearly defined protocols and realistic survey aims is capable of surveying vast areas (Ponti et al. 2011b; Cerrano et al. 2012, 2017), which increases the chances of detection of a species/phenomenon, increases replication rates and decreases individual effort (Hochachka et al. 1999; Thomas et al. 2017). This 'many eyes' effect has allowed 
citizen science to benefit landscape ecology and macroecology research by covering extensive spatio-temporal scales (Parmesan and Yohe 2003; Southward et al. 2005; Dickinson et al. 2010, 2012; Mieszkowska et al. 2014; Schläppy et al. 2017), alongside providing an efficient means for detecting species with low abundances (e.g. rare or invasive species) (Delaney et al. 2008; Dickinson et al. 2010, 2012).

\subsubsection{Marine Stewardship}

Appropriately designed projects not only have the potential to broaden the scope of marine research and policy but also reconnect participants with nature that in turn increases their awareness of the current status of the marine realm and the threats it faces (Brightsmith et al. 2008; Dickinson et al. 2010; Koss and Kingsley 2010; Garcia-Soto et al. 2017; Cerrano et al. 2017; Schläppy et al. 2017; Turicchia et al. 2017). Through marine citizen science projects, participants may observe the impact of anthropogenic activities on marine environments, which may promote a sense of ownership and drive behavioural changes towards more sustainable actions (Branchini et al. 2015; Cerrano et al. 2017). This increased awareness may then be used to promote marine stewardship, and in many cases, participants often become advocates of marine conservation (Dickinson et al. 2010; Cerrano et al. 2017; Garcia-Soto et al. 2017). The enhanced ocean literacy, resulting from participating in marine citizen science projects, combined with exposure to science through other mediums (e.g. television documentaries and news articles) (Thiel et al. 2014) may also lead to greater support for scientific advances and policy, as opposition often results from a lack of understanding of the underlying science (Schläppy et al. 2017). This environmental stewardship also forms the basis of compliance with marine management policies such as MPAs and can indirectly enhance their efficiency (Evans et al. 2008; McKinley and Fletcher 2012).

\subsection{Summary}

At present, marine citizen science is at a crossroads of demonstrated sucesses, unresolved challenges and unrealized potential (Burgess et al. 2017). To resolve these challenges, and fulfill its potential, citizen science practitioners must be willing to acknowledge project shortcomings and work together to align objectives and methodologies that ensure the generation of high-quality data sets (Burgess et al. 2017). In addition, the accessibility and feasibility of the project to a diverse array of participants, as well as methods of dissemi- nating project findings to participants, must be considered. Overall however, the projects investigated within this review demonstrated positive outcomes of collaborations between members of the public and scientists. Citizen scientists become specialized in the protocols used and in turn provide quality data that increase the spatio-temporal coverage of marine research (Thiel et al. 2014).

With our oceans and coasts in peril due to changing climatic conditions and increasing anthropogenic activities (Cigliano et al. 2015, Earp et al. 2018a), marine citizen science provides a unique platform to discover, innovate and address global challenges (i.e. species shifts and marine debris) for which data is significantly lacking (Bear 2016). As marine citizen science comes of age, although not panacea, if it successfully keeps pace with the changing contexts of marine ecological research, conservation needs and stakeholder interests, its capacity to increase ocean literacy may aid the development of culturally and politically feasible solutions for a more sustainable future (McKinley et al. 2017; Schläppy et al. 2017). With this in mind, it can be summarized that the current benefits of marine citizen science outweigh the challenges, and there is significant scope for the development and incorporation of 'science by the people' into marine research and conservation projects (Silvertown 2009).

Acknowledgements The authors are grateful for the constructive input of Dr. Siobhan Vye, Ms. Natalie Prinz and three reviewers, Dr. Ans Vercammen, Dr. Eva Turicchia and Ms. Elisabeth Morris-Webb that greatly improved the manuscript. We would also like to share our gratitude to the YOUMARES 9 committee for the opportunity to research a topic that is close to both our academic and personal experiences. Finally, our appreciation and recognition goes to all professional and citizen scientists involved in the reviewed projects for their outstanding work and commitment in making citizen science the science of the future.

\section{Appendix}

This article is related to the YOUMARES 9 conference session no. 1: "Could citizen scientists and voluntourists be the future for marine research and conservation?" The original Call for Abstracts and the abstracts of the presentations within this session can be found in the Appendix "Conference Sessions and Abstracts", Chapter "1 Could citizen scientists and voluntourists be the future for marine research and conservation?", of this book. 


\section{Supplementary Material}

Table 1.A1 Name and website of the 120 marine citizen science projects reviewed in this manuscript

\begin{tabular}{|c|c|}
\hline Marine Citizen Science Project & Website \\
\hline Angling Project: Off The Hook & www.sharktrust.org/en/anglers_recording_project \\
\hline B.C. Cetacean Sightings Network & www.wildwhales.org \\
\hline Basking Shark Project & www.sharktrust.org/en/basking_shark_project \\
\hline $\begin{array}{l}\text { Beach Environmental Assessment, Communication \& Health } \\
\text { (BEACH) }\end{array}$ & $\begin{array}{l}\text { www.ecology.wa.gov/Water-Shorelines/Water-quality/Saltwater/ } \\
\text { BEACH-program }\end{array}$ \\
\hline Beach Watch & www.beachwatch.farallones.org \\
\hline BeachObserver & www.beachobserver.com \\
\hline Big Seaweed search & www.bigseaweedsearch.org \\
\hline Birding Aboard & www.birdingaboard.org/index.html \\
\hline Biscayne Bay Drift Card Study & www.carthe.org/baydrift \\
\hline Bleach Patrol & www.ldeo.columbia.edu/bleachpatrol \\
\hline Blue Water Task Force & www.surfrider.org/blue-water-task-force \\
\hline Cape Radd Citizen Science Day & www.caperadd.com/courses/citizen-science-day \\
\hline Capturing our Coast & www.capturingourcoast.co.uk \\
\hline CARIB Tails & www.caribtails.org/home.html \\
\hline Caribbean Lionfish Response Program & www.corevi.org \\
\hline Chesapeake Bay Parasite Project & www.serc.si.edu/citizen-science/projects/chesapeake-bay-parasite-project \\
\hline Clean Sea LIFE & cleansealife.it \\
\hline Coastal Observation \& Seabird Survey Team (COASST) & www.depts.washington.edu/coasst \\
\hline $\begin{array}{l}\text { Coastal Ocean Mammal \& Bird Education \& Research Surveys } \\
\text { (Beach COMBERS) }\end{array}$ & www.mlml.calstate.edu/beachcombers \\
\hline Community Seagrass Initiative & www.csi-seagrass.co.uk \\
\hline Coral Reef Monitoring Data Portal & www.monitoring.coral.org \\
\hline CoralWatch & www.coralwatch.org \\
\hline Crab Watch & www.seachangeproject.eu/seachange-about-4/crab-watch \\
\hline Delaware Bay Horseshoe Crab Spawning Survey & $\begin{array}{l}\text { www.dnrec.alpha.delaware.gov/coastal-programs/education-outreach/ } \\
\text { horseshoe-crab-survey }\end{array}$ \\
\hline Delaware Shorebird Project & www.dnrec.delaware.gov/fw/Shorebirds \\
\hline Digital Fishers & www.oceannetworks.ca/learning/get-involved/citizen-science/digital-fishers \\
\hline divers4oceanography & www.divers4oceanography.org \\
\hline Earthdive & www.earthdive.com \\
\hline eOceans & www.eoceans.co \\
\hline Fish Watchers & www.fishbase.org/fishwatcher/menu.php \\
\hline FjordPhyto & www.fjordphyto.wordpress.com \\
\hline Floating Forests & www.zooniverse.org/projects/zooniverse/floating-forests \\
\hline Follow \& Learn About the Ocean \& Wetland (FLOW) & www.amigosdebolsachica.org/flow.php \\
\hline Global Microplastics Initiative & www.adventurescientists.org/microplastic \\
\hline Gotham Whale & www.gothamwhale.org/citizen-science \\
\hline Grunion Greeters & www.grunion.org \\
\hline Happywhale & www.happywhale.com \\
\hline Horseshoe crabs as homes & www.sites.google.com/site/epibiont \\
\hline IHO Crowdsourced Bathymetry & www.ngdc.noaa.gov/iho/\#csb \\
\hline iNaturalist & www.inaturalist.org \\
\hline Invader ID & www.zooniverse.org/projects/serc/invader-id \\
\hline iSeahorse & www.iseahorse.org \\
\hline JellyWatch & www.jellywatch.org \\
\hline Kelp Watch & www.serc.si.edu/citizen-science/projects/kelp-watch \\
\hline $\begin{array}{l}\text { Long-term Monitoring Program \& Experimental Training for } \\
\text { Students (LiMPETS) }\end{array}$ & www.limpets.org \\
\hline
\end{tabular}


Table 1.A1 (continued)

\begin{tabular}{|c|c|}
\hline Marine Citizen Science Project & Website \\
\hline Manatee Chat & www.zooniverse.org/projects/cetalingua/manatee-chat \\
\hline MangroveWatch & www.mangrovewatch.org.au \\
\hline Manta Matcher & www.mantamatcher.org/overview.jsp \\
\hline Marine Debris Monitoring \& Assessment Project & www.marinedebris.noaa.gov/research/monitoring-toolbox \\
\hline Marine Debris Tracker & www.marinedebris.engr.uga.edu \\
\hline Marine Metre Squared (Mm2) & www.mm2.net.nz \\
\hline MCS Wild Bottle Sightings & www.mcsuk.org/bottlesightings \\
\hline Mitten Crab Watch & www.mittencrabs.org.uk \\
\hline Monitor Tupinambás & www.zooniverse.org/projects/larissakawabe/monitore-tupinambas \\
\hline New England Basking Shark \& Ocean Sunfish Project & www.nebshark.org \\
\hline New York Horseshoe Crab Monitoring Network & www.nyhorseshoecrab.org \\
\hline North Atlantic Right Whale Sightings Advisory System & www.nefsc.noaa.gov/psb/surveys/SAS.html \\
\hline Ocean Sampling Day & www.microb3.eu/osd.html \\
\hline Orcasound & www.orcasound.net \\
\hline OSPAR Beach Litter & www.ospar.org/work-areas/eiha/marine-litter/beach-litter \\
\hline Our Radioactive Ocean & www.ourradioactiveocean.org \\
\hline Oyster Drills in Richardson Bay & www.serc.si.edu/citizen-science/projects/oyster-drill \\
\hline Penguin Cam & www.penguinscience.com/education/count_the_penguins.php \\
\hline Penguin Watch & www.penguinwatch.org \\
\hline Plankton Portal & www.planktonportal.org \\
\hline PlateWatch & www.platewatch.nisbase.org \\
\hline Puget Sound Seabird Survey (PSSS) & $\begin{array}{l}\text { www.seattleaudubon.org/sas/About/Science/CitizenScience/ } \\
\text { PugetSoundSeabirdSurvey.aspx }\end{array}$ \\
\hline Redmap & www.redmap.org.au \\
\hline Reef Check California & www.reefcheck.org/california/ca-overview \\
\hline Reef Check Mediterranean Sea & www.reefcheckmed.org \\
\hline Reef Check Tropical & www.reefcheck.org \\
\hline Reef Environmental Education Foundation (REEF) & www.reef.org \\
\hline Reef Life Survey & www.reeflifesurvey.com/reef-life-survey \\
\hline Reef Watch & www.conservationsa.org.au/reef_watch \\
\hline Rescue a Reef & www.sharkresearch.rsmas.miami.edu/donate/rescue-a-reef \\
\hline Satellites Over Seals (SOS) & www.tomnod.com \\
\hline Scuba Tourism For The Environment & www.steproject.org \\
\hline Sea Star Wasting Disease & www.udiscover.it/applications/seastar \\
\hline Seabird Ecological Assessment Network (SEANET) & www.seanetters.wordpress.com \\
\hline Seabirdwatch & www.zooniverse.org/projects/penguintom79/seabirdwatch \\
\hline Seagrass Spotter & www.seagrassspotter.org \\
\hline Seagrass Watch & www.seagrasswatch.org \\
\hline Sealife Survey & www.mba.ac.uk/recording/about \\
\hline Seasearch & www.seasearch.org.uk \\
\hline seaturtle.org & www.seaturtle.org \\
\hline Seawatch Submit a Sighting & www.seawatchfoundation.org.uk \\
\hline Send us your skeletons & $\begin{array}{l}\text { www.fish.wa.gov.au/Fishing-and-Aquaculture/Recreational-Fishing/ } \\
\text { Send-Us-Your-Skeletons/Pages }\end{array}$ \\
\hline Sevengill Shark Identification Project & www.sevengillsharksightings.org \\
\hline SharkBase & www.shark-base.org \\
\hline Sharkscount & www.sharksavers.org/en/our-programs/sharkscount \\
\hline Smartfin & www.surfrider.org/programs/smartfin \\
\hline Snapshots at Sea & www.zooniverse.org/projects/tedcheese/snapshots-at-sea \\
\hline South Africa Elasmobranch Monitoring (ELMO) & www.elmoafrica.org \\
\hline SubseaObservers & www.subseaobservers.com \\
\hline Tag A Tiny & www.umb.edu/tunalab/tagatiny \\
\hline Tangaroa Blue & www.tangaroablue.org \\
\hline
\end{tabular}


Table 1.A1 (continued)

\begin{tabular}{l|l}
\hline Marine Citizen Science Project & Website \\
\hline TBF Tag \& Release Program & www.billfish.org/research/tag-and-release \\
\hline The Big Sea Survey & www.hlf.org.uk/our-projects/big-sea-survey \\
\hline The Florida Keys BleachWatch Program & $\begin{array}{l}\text { www.mote.org/research/program/coral-reef-science-monitoring/ } \\
\text { bleachwatch }\end{array}$ \\
\hline The Great Eggcase Hunt Project & www.sharktrust.org/en/great_eggcase_hunt \\
\hline The Great Nurdle Hunt & www.nurdlehunt.org.uk \\
\hline The Plastic Tide & www.theplastictide.com \\
\hline The Secchi Disk study & www.secchidisk.org \\
\hline The Shore Thing & www.mba.ac.uk/shore_thing \\
\hline The Wetland Bird Survey (WeBS) & www.bto.org/volunteer-surveys/webs \\
\hline TLC Juvenile Lobster Monitoring Program & www.lobsters.org/volunt/volunteer.html \\
\hline trackmyfish & trackmy.fish \\
\hline Wakame Watch & wakamewatch.org.uk \\
\hline WDC Shorewatch Programme & www.wdcs.org/national_regions/scotland/shorewatch \\
\hline Weddell Seal Count & www.zooniverse.org/projects/slg0808/weddell-seal-count \\
\hline Whale FM & whale.fm \\
\hline Whale mAPP & www.whalemapp.org \\
\hline Whale Track & whaletrack.hwdt.org \\
\hline Whales as Individuals & www.zooniverse.org/projects/tedcheese/whales-as-individuals \\
\hline Wildbook for Whale Sharks & www.whaleshark.org \\
\hline All websites last accessed 24 June 2019 by the authors & \\
\hline
\end{tabular}

All websites last accessed 24 June 2019 by the authors

\section{References}

Adams CM, Shumway SE, Whitlatch RB et al (2011) Biofouling in marine molluscan shellfish aquaculture: a survey assessing the business and economic implications of mitigation. J World Aquacult Soc 42:242-252. https://doi.org/10.1111/j.1749-7345.2011.00460.x

Avens L, Taylor JC, Goshe LR et al (2009) Use of skeletochronological analysis to estimate the age of leatherback sea turtles Dermochelys coriacea in the western North Atlantic. Endanger Species Res 8:165-177. https://doi.org/10.3354/esr00202

Bax N, Carlton JT, Mathews-Amos A et al (2001) The control of biological invasions in the world's oceans. Conserv Biol 15:12341246. https://doi.org/10.1111/j.1523-1739.2001.99487.x

Bear M (2016) Perspectives in marine citizen science. J Microbiol Biol Educ 17(1):56-59. https://doi.org/10.1128/jmbe.v17i1.1037

Bell JJ (2007) The use of volunteers for conducting sponge biodiversity assessments and monitoring using a morphological approach on Indo-Pacific coral reefs. Aquat Conserv 17:133-145. https://doi. org/10.1002/aqc.789

Bird TJ, Bates AE, Lefcheck JS et al (2014) Statistical solutions for error and bias in global citizen science datasets. Biol Conserv 173:144-154. https://doi.org/10.1016/j.biocon.2013.07.037

Bonney R, Cooper CB, Dickinson J et al (2009) Citizen science: a developing tool for expanding science knowledge and scientific literacy. Bioscience 59(11):977-984. https://doi.org/10.1525/ bio.2009.59.11.9

Bonney R, Shirk JL, Phillips TB et al (2014) Next steps for citizen science. Science 343(6178):1436-1437. https://doi.org/10.1126/ science. 1251554

Bonney R, Phillips TB, Ballard HL et al (2016a) Can citizen science enhance public understanding of science? Public Underst Sci 25(1):2-16. https://doi.org/10.1177/0963662515607406

Bonney R, Cooper C, Ballard HL (2016b) The theory and practice of citizen science: launching a new journal. CSTP 1(1):1-4. https:// doi.org/10.5334/cstp.65

Bowen S, Goodwin C, Kipling D et al (2011) Sea squirts and sponges of Britain and Ireland. Seasearch guides. Wild Nature Press, Plymouth
Branchini S, Pensa F, Neri P et al (2015) Using a citizen science program to monitor coral reef biodiversity through space and time. Biodivers Conserv 24:319-336. https://doi.org/10.1007/s10531-014-0810-7

Bravo M, Gallardo M, Luna-Jorquera G et al (2009) Anthropogenic debris on beaches in the SE Pacific (Chile): results from a national survey supported by volunteers. Mar Pollut Bull 58:1718-1726. https://doi.org/10.1016/j.marpolbul.2009.06.017

Brightsmith DJ, Stronza A, Holle K (2008) Ecotourism, conservation biology, and volunteer tourism: a mutually beneficial triumvirate. Biol Conserv 141:2832-2842. https://doi.org/10.1016/j. biocon.2008.08.020

Bruce E, Albright L, Sheehan S et al (2014) Distribution patterns of migrating humpback whales (Megaptera novaeangliae) in Jervis Bay, Australia: a spatial analysis using geographical citizen science data. Appl Geogr 54:83-95. https://doi.org/10.1016/j. apgeog.2014.06.014

Bunker FSPD, Brodie JA, Maggs CA et al (2017) Seaweeds of Britain and Ireland, Seasearch guides, 2nd edn. Wild Nature Press, Plymouth

Burgess HK, DeBey LB, Froehlich HE et al (2017) The science of citizen science: exploring barriers to use as a primary research tool. Biol Conserv 208:113-120. https://doi.org/10.1016/j. biocon.2016.05.014

Campbell LM, Smith C (2006) What makes them pay? Values of volunteer tourists working for sea turtle conservation. Environ Manag 38:84-98. https://doi.org/10.1007/s00267-005-0188-0

Cerrano C, Di Camillo CG, Milanese M et al (2012) Education through participation: the role of citizen science in marine habitat conservation. PIXEL New perspectives in science education, Florence

Cerrano C, Milanese M, Ponti M (2017) Diving for science - science for diving: volunteer scuba divers support science and conservation in the Mediterranean Sea. Aquat Conserv 27:303-323. https://doi. org/10.1002/aqc. 2663

Chamberlain J (2018) Purple octopus. http://www.purpleoctopus.org/ groupsourcing/. Accessed 9 Oct 2018

Cheung WW, Lam VW, Sarmiento JL et al (2009) Projecting global marine biodiversity impacts under climate 
change scenarios. Fish Fish 10(3):235-251. https://doi. org/10.1111/j.1467-2979.2008.00315.x

Cigliano JA, Ballard HL (2018) Citizen science for coastal and marine conservation. Routledge, Abingdon

Cigliano JA, Meyer R, Ballard HL et al (2015) Making marine and coastal citizen science matter. Ocean Coast Manage 115:77-87. https://doi.org/10.1016/j.ocecoaman.2015.06.012

Cohen CS, McCann L, Davis T et al (2011) Discovery and significance of the colonial tunicate Didemnum vexillum in Alaska. Aquat Invasions 6(3):263-271. https://doi.org/10.3391/ai.2011.6.3

Cohn JP (2008) Citizen science: can volunteers do real research? Bioscience 58(3):192-197. https://doi.org/10.1641/B580303

Conrad CT, Daoust T (2008) Community-based monitoring frameworks: increasing the effectiveness of environmental stewardship. Environ Manag 41(3):358-366. https://doi.org/10.1007/ s00267-007-9042-x

Conrad CC, Hilchey KG (2011) A review of citizen science and community-based environmental monitoring: issues and opportunities. Environ Monit Assess 176(1-4):273-291. https://doi. org/10.1007/s10661-010-1582-5

Courter JR, Johnson RJ, Stuyck CM et al (2013) Weekend bias in citizen science data reporting: implications for phenology studies. Int J Biometeorol 57(5):715-720. https://doi.org/10.1007/ s00484-012-0598-7

Cox TE, Philippoff J, Baumgartner E et al (2012) Expert variability provides perspective on the strengths and weaknesses of citizen-driven intertidal monitoring program. Ecol Appl 22(4):1201-1212. https:// doi.org/10.1890/11-1614.1

Cox J, Oh EY, Simmons B et al (2015) Defining and measuring success in online citizen science: a case study of Zooniverse projects. Comput Sci Eng 17(4):28-41. https://doi.org/10.1109/ MCSE. 2015.65

Crabbe MJC (2012) From citizen science to policy development on the coral reefs of Jamaica. Int J Zool:102350. https://doi. org/10.1155/2012/102350

Culver CS, Schroeter SC, Page HM et al (2010) Essential fishery information for trap-based fisheries: development of a framework for collaborative data collection. Mar Coast Fish 2:98-114. https://doi. org/10.1577/C09-007.1

Danielsen F, Pirhofer-Walzl K, Adrian TP et al (2013) Linking public participation in scientific research to the indicators and needs of international environmental agreements. Conserv Lett 7(1):12-24. https://doi.org/10.1111/conl.12024

Delaney DG, Sperling CD, Adams CS et al (2008) Marine invasive species: validation of citizen science and implications for national monitoring networks. Biol Invasions 10(1):117-128. https://doi. org/10.1007/s10530-007-9114-0

Dickinson JL, Zuckerberg B, Bonter DN (2010) Citizen science as an ecological research tool: challenges and benefits. Annu Rev Ecol Evol Syst 41:149-172. https://doi.org/10.1146/ annurev-ecolsys-102209-144636

Dickinson JL, Shirk J, Bonter D et al (2012) The current state of citizen science as a tool for ecological research and public engagement. Front Ecol Environ 10(6):291-297. https://doi.org/10.1890/110236

Directive 2008/56/EC of the European Parliament and of the Council (2008) Establishing a framework for community action in the field of marine environmental policy (Marine Strategy Framework Directive). Off J Eur Union 164:19-40

Done T, Roelfsema C, Harvey A et al (2017) Reliability and utility of citizen science reef monitoring data collected by Reef Check Australia, 2002-2015. Mar Pollut Bull 117(1-2):148-155. https:// doi.org/10.1016/j.marpolbul.2017.01.054

Earp HS, Prinz N, Cziesielski MJ et al (2018a) For a world without boundaries: connectivity between marine tropical ecosystems in times of change. In: Jungblut S, Liebich V, Bode M (eds) YOUMARES 8 - oceans across boundaries: learning from each other. Springer, Cham, pp 125-144. https://doi.org/10.1007/978-3-319-93284-2_9
Earp HS, Vye SR, West V et al (2018b) Do you see what I see? Quantifying inter-observer variability in an intertidal disturbance experiment. Poster presented at YOUMARES 9, University of Oldenburg, Germany, 11-14 September 2018

Edgar GJ, Stuart-Smith RD (2009) Ecological effects of marine protected areas on rocky reef communitie - a continental-scale analysis. Mar Ecol Prog Ser 388:51-62. https://doi.org/10.3354/meps08149

Embling CB, Walters AEM, Dolman SJ (2015) How much effort is enough? The power of citizen science to monitor trends in coastal cetacean species. Glob Ecol Conserv 3:867-877. https://doi. org/10.1016/j.gecco.2015.04.003

Eriksen M, Lebreton LCM, Carson HS et al (2014) Plastic pollution in the world's oceans: more than 5 trillion plastic pieces weighing over 250,000 tons afloat at sea. PLoS One 9:e111913. https://doi. org/10.1371/journal.pone.0111913

Evans SM, Gebbels S, Stockill JM (2008) 'Our shared responsibility': participation in ecological projects as a means of empowering communities to contribute to coastal management processes. Mar Pollut Bull 57:3-7. https://doi.org/10.1016/j.marpolbul.2008.04.014

Fore LS, Paulsen K, O'Laughlin K (2001) Assessing the performance of volunteers in monitoring streams. Freshw Biol 46(1):109-123. https://doi.org/10.1111/j.1365-2427.2001.00640.x

Forrester G, Baily P, Conetta D et al (2015) Comparing monitoring data collected by volunteers and professionals shows that citizen scientists can detect long-term change on coral reefs. J Nat Conserv 24:1-9. https://doi.org/10.1016/j.jnc.2015.01.002

Foster-Smith J, Evans SM (2003) The value of marine ecological data collected by volunteers. Biol Conserv 113(2):199-213. https://doi. org/10.1016/S0006-3207(02)00373-7

Garcia-Soto C, van der Meeren GI, Busch JA et al (2017) Advancing citizen science for coastal and ocean research. In: French V, Kellett P, Delany J et al (eds) Position Paper 23 of the European Marine Board, Ostend, Belgium

Geller JB, Walton ED, Grosholz ED et al (1997) Cryptic invasions of the crab Carcinus detected by molecular phylogeography. Mol Ecol 6:901-906. https://doi.org/10.1046/j.1365-294X.1997.00256.x

Gouraguine A, Moranta J, Ruiz-Frau A et al (2019) Citizen science in data and resource-limited areas: A tool to detect long-term ecosystem changes. PloS One 14 (1):e0210007. https://doi.org/10.1371/ journal.pone. 0210007

Haklay M (2015) Citizen science and policy: a European perspective. The Woodrow Wilson Center, Washington, DC

Hidalgo-Ruz V, Thiel M (2013) Distribution and abundance of small plastic debris on beaches in the SE Pacific (Chile): a study supported by a citizen science project. Mar Environ Res 87:12-18. https://doi.org/10.1016/j.marenvres.2013.02.015

Hidalgo-Ruz V, Thiel M (2015) The contribution of citizen scientists to the monitoring of marine litter. In: Bergmann M, Gutow L, Klages M (eds) Marine anthropogenic litter. Springer, Cham, pp 429-447

Hobson B (2000) Recreation specialization revisited. J Leis Res $32: 18-21$

Hochachka WM, Wells JV, Rosenberg KV (1999) Irruptive migration of common redpolls. Condor 101:195-204

Hochachka WM, Fink D, Hutchinson RA et al (2012) Data-intensive science applied to broad-scale citizen science. Trends Ecol Evol 27(2):130-137. https://doi.org/10.1016/j.tree.2011.11.006

Holt BG, Rioja-Nieto R, MacNeil MA et al (2013) Comparing diversity data collected using a protocol designed for volunteers with results from a professional alternative. Methods Ecol Evol 4:383-392. https://doi.org/10.1111/2041-210X.12031

Hyder K, Townhill B, Anderson LG et al (2015) Can citizen science contribute to the evidence-base that underpins marine policy? Mar Policy 59:112-120. https://doi.org/10.1016/j.marpol.2015.04.022

Jarvis RM, Breen BB, Krägeloh CU et al (2015) Citizen science and the power of public participation in marine spatial planning. Mar Policy 57:21-26. https://doi.org/10.1016/j.marpol.2015.03.011 
Jiguet F (2009) Method learning caused a first-time observer effect in a newly started breeding bird survey. Bird Study 56(2):253-258. https://doi.org/10.1080/00063650902791991

Jordan R, Crall A, Gray S et al (2015) Citizen science as a distinct field of inquiry. Bioscience 65(2):208-211. https://doi.org/10.1093/ biosci/biu217

Kay P, Dipper F (2018) A field guide to marine fishes of wales and adjacent waters. Marine Conservation Society and Countryside Council for Wales, Marine Wildlife, Conwy

Kerson R (1989) Lab for the environment. MITS Technol Rev 92(1):11-12

Kosmala M, Wiggins A, Swanson A et al (2016) Assessing data quality in citizen science. Front Ecol Environ 14(10):551-560. https://doi. org/10.1002/fee. 1436

Koss RS, Kingsley JY (2010) Volunteer health and emotional wellbeing in marine protected areas. Ocean Coast Manag 53:447-453. https:// doi.org/10.1016/j.ocecoaman.2010.06.002

Kullenberg C, Kasperowski D (2016) What is citizen science? A scientometric meta-analysis. PLoS One 11(1):e0147152. https://doi. org/10.1371/journal.pone.0147152

Lima $S$ (1995) Back to the basics of anti-predatory vigilance: the group-size effect. Anim Behav 49(1):11-20. https://doi. org/10.1016/0003-3472(95)80149-9

Lohrer AM (2001) The invasion by Hemigrapsus sanguineus in eastern North America: a review. Aquat Invaders 12(3):1-11

Markantonatou V, Meidinger M, Sano M et al (2013) Stakeholder participation and the use of web technology for MPA management. Adv Oceanogr Limnol 4:260-276. https://doi.org/10.1080/194757 21.2013.851117

Marshall NJ, Kleine DA, Dean AJ (2012) CoralWatch: education, monitoring, and sustainability through citizen science. Front Ecol Environ 10(6):332-334. https://doi.org/10.1890/110266

Martin JM (2013) Marine debris removal: one year of effort by the Georgia Sea turtle-center-marine debris initiative. Mar Pollut Bull 74:165-169. https://doi.org/10.1016/j.marpolbul.2013.07.009

Martin VY, Christidis L, Pecl GT (2016) Public interest in marine citizen science: is there potential for growth? Bioscience 66(8):683692. https://doi.org/10.1093/biosci/biw070

McGehee NG (2014) Volunteer tourism: evolution, issues and futures. J Sustain Tour 22(6):847-854. https://doi.org/10.1080/09669582.2 014.907299

McGovern B, Culloch RM, O'Connell M et al (2016) Temporal and spatial trends in stranding records of cetaceans on the Irish coast, 2002-2014. J Mar Biol Assoc UK 98(5):977-989. https://doi. org/10.1017/S0025315416001594

McKinley E, Fletcher S (2012) Improving marine environmental health through marine citizenship: a call for debate. Mar Policy 36:839843. https://doi.org/10.1016/j.marpol.2011.11.001

McKinley DC, Miller-Rushing AJ, Ballard HL et al (2017) Citizen science can improve conservation science, natural resource management, and environmental protection. Biol Conserv 208:15-28. https://doi.org/10.1016/j.biocon.2016.05.015

Mieszkowska N, Sugden H, Firth LB et al (2014) The role of sustained observations in tracking impacts of environmental change on marine biodiversity and ecosystems. Philos Trans R Soc A 372(2025):20130339. https://doi.org/10.1098/rsta.2013.0339

Nelms SE, Coombes C, Foster LC et al (2017) Marine anthropogenic litter on British beaches: a 10-year nationwide assessment using citizen science data. Sci Total Environ 579:1399-1409. https://doi. org/10.1016/j.scitotenv.2016.11.137

Newman S, Watkins E, Farmer A et al (2015) The economics of marine litter. In: Bergmann M, Gutow L, Klages M (eds) Marine anthropogenic litter. Springer, Cham, pp 367-394

Ocean Networks Canada (2018) Digital fishers. www.oceannetworks. ca/learning/get-involved/citizen-science/digital-fishers. Accessed 24 Sept 2018
OED Online (2018a) "citizen, n. and adj.". Oxford University Press. www.oed.com/view/Entry/33513?redirectedFrom=citizen+science. Accessed 22 Apr 2018

OED Online (2018b) "voluntourism, n.". Oxford University Press. www.oed.com/view/Entry/34245729\#eid1151399030. Accessed 3 Oct 2018

OSPAR (2010) Guideline for monitoring marine litter on the beaches in the OSPAR maritime area. OSPAR Commission. www.ospar.org/ ospar-data/10-02e_beachlitter\%20guideline_english\%20only.pdf. Accessed 30 May 2018

Parmesan C, Yohe G (2003) A globally coherent fingerprint of climate change impacts across natural systems. Nature 421:37-42. https:// doi.org/10.1038/nature01286

Parr J, Sewell J (2017) Citizen sentinels: the role of citizen scientists in reporting and monitoring invasive non-native species. In: Cigliano JA, Ballard HL (eds) Citizen science for coastal and marine conservation. Routledge, London, pp 59-76

Ponti M, Rossi G, Bertolino M et al (2011a) Reef Check: involvement of SCUBA diver volunteers in the Coastal Environment Monitoring Protocol for the Mediterranean Sea Abstracts of the 9th International Temperate Reefs Symposium, Plymouth, p 164

Ponti M, Leoni G, Abbiati M (2011b) Geographical analysis of marine species distribution data provided by diver volunteers. Biol Mar Mediterr 18:282-283

Prestopnik NR, Crowston K (2011) Gaming for (citizen) science: exploring motivation and data quality in the context of crowdsourced science through the design and evaluation of a social-computational system. In: Proceedings of the 7th IEEE International Conference on e-Science Workshops, IEE Computer Society, Stockholm, pp 28-33

Reef Check (2018) EcoDiver courses and products. www.reefcheck. org/ecodiver/reef-check-ecodiver. Accessed 18 May 2018

Ribic CA (1998) Use of indicator items to monitor marine debris on a New Jersey beach from 1991 to 1996. Mar Pollut Bull 36:887-891

Ribic CA, Sheavly SB, Rugg DJ (2011) Trends in marine debris in the US Caribbean and the Gulf of Mexico 1996-2003. JICZM/RGCI 11:7-19

Ricciardi A, Mack RN, Steiner WM et al (2000) Toward a global information system for invasive species. Bioscience 50:239-244

Riesch H, Potter C (2014) Citizen science as seen by scientists: methodological, epistemological and ethical dimensions. Public Underst Sci 23(1):107-120. https://doi.org/10.1177/0963662513497324

Robertson MP, Cumming GS, Erasmus BFN (2010) Getting the most out of atlas data. Divers Distrib 16(3):363-375. https://doi. org/10.1111/j.1472-4642.2010.00639.x

Root T, Alpert P (1994) Volunteers and the NBS. Science 263(5151):1205. https://doi.org/10.1126/science.263.5151.1205

Rotman D, Preece J, Hammock J et al (2012) Dynamic changes in motivation in collaborative citizen-science projects. In: Proceedings of the ACM conference on computer supported cooperative work, CSCW, Seattle, pp 217-226

Roy HE, Pocock MJ, Preston CD et al (2012) Understanding citizen science and environmental monitoring: final report on behalf of UK-EOF. NERC Centre for Ecology \& Hydrology and Natural History Museum, London, pp 1-170

Ruiz GM, Hines AH, Carlton JT et al (1997) Global invasions of marine and estuarine habitats by non-indigenous species: mechanisms, extent, and consequences. Integr Comp Biol 37:621-632

Ryan PG, Moore CJ, van Franeker JA et al (2009) Monitoring the abundance of plastic debris in the marine environment. Philos Trans $\mathrm{R}$ Soc B 364:1999-2012. https://doi.org/10.1098/rstb.2008.0207

Schläppy ML, Loder J, Salmond J et al (2017) Making waves: marine citizen science for impact. Front Mar Sci 4:146. https://doi. org/10.3389/fmars.2017.00146

Science Communication Unit, University of the West of England, Bristol (2013) Science for Environment Policy In-depth Report: Environmental Citizen Science. Report produced for the European 
Commission DG Environment, December 2013. Available at: www. ec.europa.eu/science-environment-policy

Seasearch (2018) Seasearch diving. www.seasearch.org.uk/diving. html. Accessed 18 May 2018

Silvertown J (2009) A new dawn for citizen science. Trends Ecol Evol 24(9):467-471. https://doi.org/10.1016/j.tree.2009.03.017

Southward AJ, Langmead O, Hardman-Mountford NJ et al (2005) Long-term oceanographic and ecological research in the Western English Channel. Adv Mar Biol 47:1-105. https://doi.org/10.1016/ S0065-2881(04)47001-1

Stafford R, Hart AG, Collins L et al (2010) Eu-social science: the role of internet social networks in the collection of bee biodiversity data. PLoS One 5(12):e14381. https://doi.org/10.1371/journal. pone.0014381

Sundlov T, Graham M, Davis T et al (2016) Sea squirt Invades BLM submerged lands in Southeast Alaska. U.S. Department of the Interior: Bureau of Land Management. www.blm.gov/blog/201610-14/sea-squirt-invades-blm-submerged-lands-southeast-alaska. Accessed 9 Apr 2018

Teleki KA (2012) Power of the people? Aquatic Conserv 22(1):1-6. https://doi.org/10.1002/aqc.2219

Theobald EJ, Ettinger AK, Burgess HK et al (2015) Global change and local solutions: tapping the unrealized potential of citizen science for biodiversity research. Biol Conserv 181:236-244. https://doi. org/10.1016/j.biocon.2014.10.021

Thiel M, Penna-Díaz MA, Luna-Jorquera G et al (2014) Citizen scientists and marine research: volunteer participants, their contributions, and projection for the future. Oceanogr Mar Biol 52:257-314. https://doi.org/10.1201/b17143-6

Thomas LM, Gunawardene N, Horton K et al (2017) Many eyes on the ground: citizen science is an effective early detection tool for biosecurity. Biol Invasions 19(9):2751-2765. https://doi.org/10.1007/ s10530-017-1481-6

Tonachella N, Nastasi A, Kaufman G et al (2012) Predicting trends in humpback whale (Megaptera novaeangliae) abundance using citizen science. Pac Conserv Biol 18(4):297-309
Tulloch AI, Possingham HP, Joseph LN et al (2013) Realising the full potential of citizen science monitoring programs. Biol Conserv 165:128-138. https://doi.org/10.1016/j.biocon.2013.05.025

Turicchia E, Ponti M, Abbiati M et al (2015) Citizen science as a tool for the environmental quality assessment of Mediterranean Marine Protected Areas. In: Cerrano C, Henocque Y, Hogg K et al (eds) Proceedings of the MMMPA/CIESM international joint conference on Mediterranean marine protected areas: integrated management as a response to ecosystem threats. Ancona, Italy, p 29

Turicchia E, Abbiati M, Cerrano C et al (2017) May citizen science effectively support underwater monitoring programs? 3rd European conference on scientific diving book of abstracts. Funchal, Portugal, p 46

UNCTADstat (2018) United Nations conference on trade and development. Country classifications. unctadstat.unctad.org/EN/ Classifications.html. Accessed 9 Oct 2018

van der Velde T, Milton DA, Lawson TJ et al (2017) Comparison of marine debris data collected by researchers and citizen scientists: is citizen science data worth the effort? Biol Conserv 208:127-138. https://doi.org/10.1016/j.biocon.2016.05.025

Van Franeker JA, Blaize C, Danielsen J et al (2011) Monitoring plastic ingestion by the northern fulmar Fulmarus glacialis in the North Sea. Environ Pollut 159:2609-2615. https://doi.org/10.1016/j. envpol.2011.06.008

Visser ME, Both C (2005) Shifts in phenology due to global climate change: the need for a yardstick. Proc R Soc Lond B Biol 272(1581):2561-2569. https://doi.org/10.1098/rspb.2005.3356

Watson DI, Shumway SE, Whitlatch RB (2009) Biofouling and the shellfish industry. In: Shumway SE, Rodrick GE (eds) Shellfish safety and quality. Woodhead Publishing Ltd., Cambridge

Wiggins A, Crowston K (2011) From conservation to crowdsourcing: a typology of citizen science. HICSS ' 11 Proceedings of the 44th Hawaii international conference on system sciences, pp 1-10

Worthington JP, Silvertown J, Cook L et al (2012) Evolution MegaLab: a case study in citizen science methods. Methods Ecol Evol 3(2):303-309. https://doi.org/10.1111/j.2041-210X.2011.00164.x

Open Access This chapter is licensed under the terms of the Creative Commons Attribution 4.0 International License (http://creativecommons. org/licenses/by/4.0/), which permits use, sharing, adaptation, distribution and reproduction in any medium or format, as long as you give appropriate credit to the original author(s) and the source, provide a link to the Creative Commons license and indicate if changes were made.

The images or other third party material in this chapter are included in the chapter's Creative Commons license, unless indicated otherwise in a credit line to the material. If material is not included in the chapter's Creative Commons license and your intended use is not permitted by statutory regulation or exceeds the permitted use, you will need to obtain permission directly from the copyright holder. 